Review

\title{
Botanical compounds and their regulation of nuclear receptor action: The case of traditional Chinese medicine
}

\author{
Ling Li ${ }^{\mathrm{a}, \mathrm{b}}$, François Bonneton ${ }^{\mathrm{a}}$, Xiao Yong Chen ${ }^{\mathrm{b}}$, Vincent Laudet ${ }^{\mathrm{a}, *}$ \\ a Institut de Génomique Fonctionnelle de Lyon; Université de Lyon; Université Lyon 1; CNRS UMR 5242; Ecole Normale Supérieure de Lyon, France. \\ b School of Ecological and Environmental Science, East China Normal University, Shanghai, China
}

\section{A R T I C L E I N F O}

\section{Article history:}

Received 3 October 2014

Received in revised form 23 October 2014

Accepted 31 October 2014

Available online 6 November 2014

\section{Keywords:}

Nuclear receptor

Traditional Chinese medicine

Pharmacology

Agonist

Antagonist

\begin{abstract}
A B S T R A C T
Nuclear receptors (NRs) are major pharmacological targets that allow an access to the mechanisms controlling gene regulation. As such, some NRs were identified as biological targets of active compounds contained in herbal remedies found in traditional medicines. We aim here to review this expanding literature by focusing on the informative articles regarding the mechanisms of action of traditional Chinese medicines (TCMs). We exemplified well-characterized TCM action mediated by NR such as steroid receptors (ER, GR, AR), metabolic receptors (PPAR, LXR, FXR, PXR, CAR) and RXR. We also provided, when possible, examples from other traditional medicines. From these, we draw a parallel between TCMs and phytoestrogens or endocrine disrupting chemicals also acting via NR. We define common principle of action and highlight the potential and limits of those compounds. TCMs, by finely tuning physiological reactions in positive and negative manners, could act, in a subtle but efficient way, on NR sensors and their transcriptional network.
\end{abstract}

\section{Contents}

1. Traditional medicines and herbal compounds

2. Why study the effects of TCM on nuclear receptors? ..................................................................................................................................................... 223

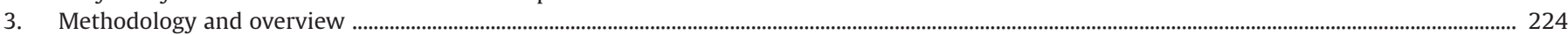

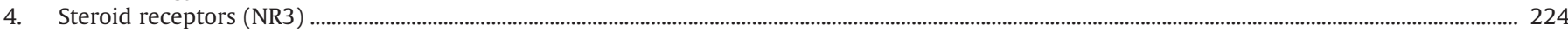

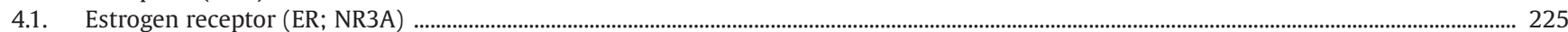

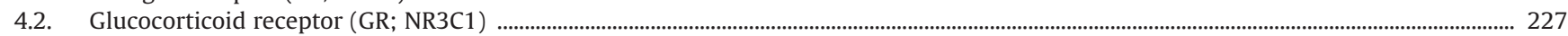

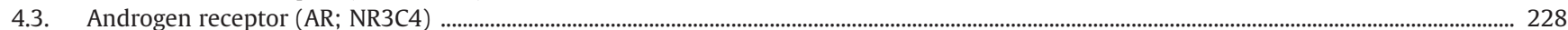

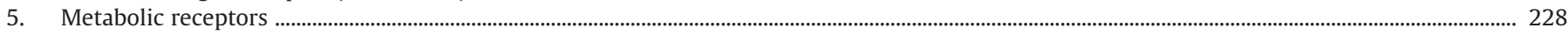

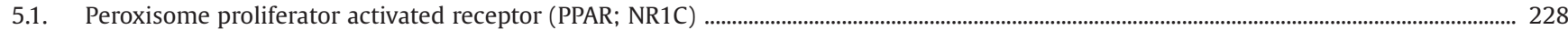

5.2. Liver X receptor and farnesoid X receptor (LXR, FXR; NR1H) …...................................................................................................................... 229

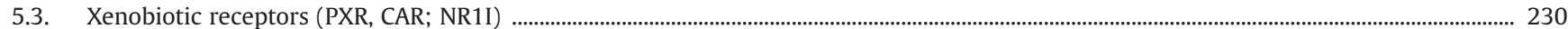

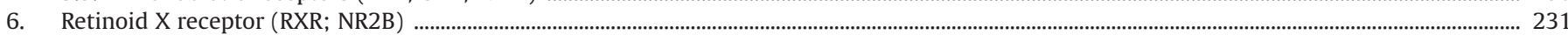

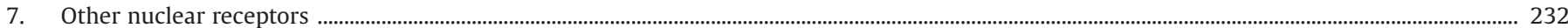

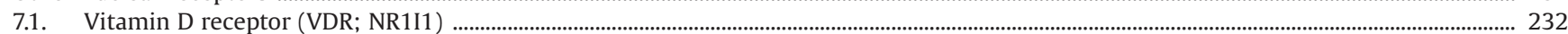

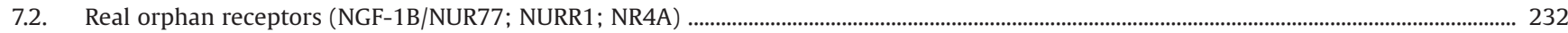

8. Conclusion: when nuclear receptors meet traditional Chinese medicine …………………………………………………………………….... 232

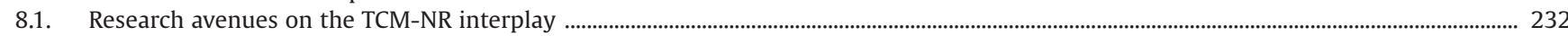

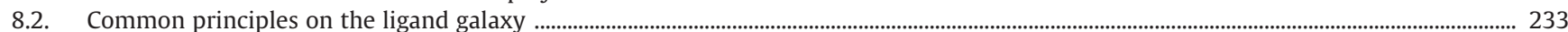

Abbreviations: AR, androgen receptor; CAR, constitutive androstane receptor; DBD, DNA-binding domain; EDC, endocrine disrupting chemical; ER, estrogen receptor;

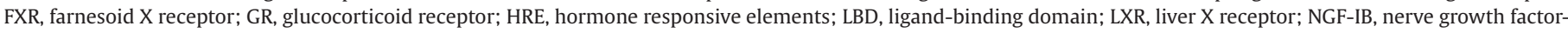

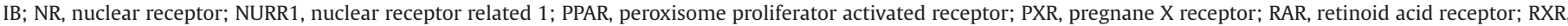

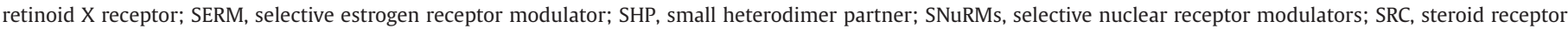
coactivator; TCM, traditional Chinese medicine; TR, thyroid receptor; VDR, vitamin D receptor.

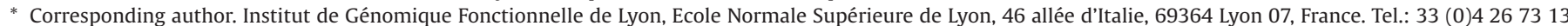
76; fax: 33 (0)4 26731375 .

E-mail address: Vincent.Laudet@ens-lyon.fr (V. Laudet). 


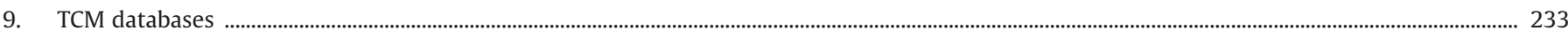

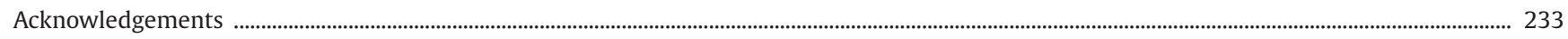

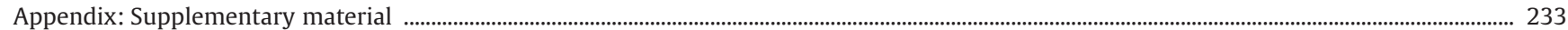

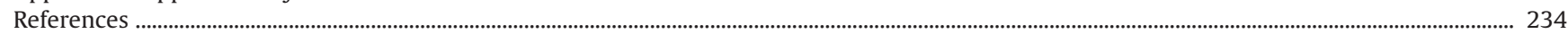

\section{Traditional medicines and herbal compounds}

Since plants are at the origin of western pharmacopeia, we can say that traditional medicines were a major source of the modern pharmaceutical industry. An important approach of western medicine has been to use the therapeutic effect of plants in order to identify the active molecule and to chemically synthetize it. In many cases, studying the derivatives of such compounds allowed to improve the efficacy or specificity of the biological effect (Corson and Crews, 2007). This is the case of the well-known aspirin, derived from salicylic acid present in the bark of willow trees (genus Salix) traditionally used to treat fever and inflammation. In modern western medicine the purification of single molecules is in fact a prerequisite to the marketing of a drug. Indeed, to register a drug, one should have a single molecule with a well-characterized biological effect on specific targets that should be used to treat a specific disease. By contrast to this reductionist approach, traditional medicine rely on the effects observed by complex mixtures of molecules obtained directly from crude plant extracts. This is well exemplified by traditional Chinese medicine (TCM). In this review, we will focus on botanical compounds from TCM because it is one of the most ancient and commonly used medicines with a well-defined medical corpus. Indeed, from the "Divine Farmer's Materia Medica" (Shen Nong Ben Cao Jing, 神农本草经), the oldest Chinese book on agricultural and medical plants that describes more than 300 traditional Chinese drugs (Wang et al., 2007), to the "Compendium of Materia Medica" (Ben Cao Gang Mu-本草纲目), the most complete and comprehensive text written by Li Shi Zhen in the sixteenth century (Tian and Huang, 2007), an abundant and ancient Chinese medical literature is still the source of remedies in the treatment of many diseases (May et al., 2012). Currently, almost 100,000 TCM preparations using 11,000 kinds of herbs, 300 minerals and animal extracts are used in China to treat more than 3700 diseases (Qiu, 2007). Furthermore, TCM has gained increasing attention from the western health-care systems (Scheid, 1999), which raises important issues regarding the scientific nature of some of its practices. Our approach could be fruitfully applied to other traditional medicines, and we provide some examples. However, an exhaustive analysis of all traditional medicine would be beyond the scope of this synthesis.

An important principle used to prepare TCM drug is to restore the internal balance by combining ingredients, which is thought to be more effective than application of a single compound (Chen et al., 2010). This illustrates very well the major conceptual and practical differences between western medicine (based on single compound isolation) and TCM (based on the combination of several ingredients). TCM compound formulae (fufang) (Fig. 1) contain several plants, among which one represents the active component (the sovereign), and the others serve as adjuvant to assist the effects (additivity, synergy) or to facilitate the delivery (detoxification, compatibility) of the principal component (Tian, 2011).

It is thought that multiple components can hit multiple targets and exert synergistic effects with less toxicity than one purified compound (Li and Zhang, 2008). This combination therapy is more complex than biomedical pharmacology and therefore it has rarely been scientifically tested. As an example, the Realgar-Indigo naturalis formula (RIF) has been proven to be effective in treating human acute promyelocytic leukemia (APL), a cancer induced by the fusion protein PML-RAR $\alpha$. An arsenic sulfide mineral (realgar) is the principal element of RIF, while three plants (Indigo naturalis,
Salviae miltiorrhizae and Pseudostellaria heterophylla) play the role of adjuvants. It is the combination of tetraarsenic tetrasulfide $\left(\mathrm{As}_{4} \mathrm{~S}_{4}\right)$, indirubin (from Indigo naturalis), and tanshinone IIA (from Salvia miltiorrhizae) that yields synergy in the treatment of a murine APL model in vivo (Wang et al., 2008). This use of arsenic to treat APL in TCM is striking, given that arsenic trioxide combined with retinoic acid is now a treatment of choice in western medicine to cure APL and indeed the use of arsenic for such a purpose was pioneered in northern China (Lo-Coco et al., 2013; Shen et al., 1997).

Nevertheless, such promising examples are rare and raise several questions regarding the future of TCM. First, how do mixtures of ingredients act in concert? Indeed, in contrast with western pharmacology, the active compounds and their mechanisms of action are usually unknown for TCM products, which treat the symptoms rather than the cause of disease (Chan, 1995). That is why "westernization" of TCMs is considered as a necessary step to understand their principles of action. This is a huge task, if we consider that almost 7000 compounds have already been isolated from TCM formulae, acting on more than 17,000 targets (Chen, 2011; Xue et al., 2013). A successful example of such an approach is artemisinin (qinghaosu), a new antimalarial drug, which was isolated from Artemisia annua, a plant used in China for almost 2000 years in the treatment of malaria (Wang et al., 2007; Miller and Su 2011; Tu, 2011). Because TCM has a holistic approach, system biology and -omics technologies are probably the most appropriate ways to understand the mechanisms that underlie the therapeutic effects of these mixtures (Qiu, 2007; Tian, 2011). Recent projects go in this direction, such as "Fangjiomics" that aims to identify and design effective mixtures of bioactive agents and elucidating their modes of action (Wang et al., 2011), while "Chinmedomics" refers to the metabolomics of TCM formulae (Wang et al., 2012a). Large noncommercial TCM databases have been constructed to support those efforts (Chen, 2011; Xue et al., 2013). Another concern is that the use of TCM has sometimes been associated with adverse effects, such as hepatotoxicity (Chen et al., 2011). As for any herbal treatment, variations in geographical or seasonal growth locations and harvest time have potential impacts on toxicity and safety of the product (Li et al., 2005; Wu et al., 2007). It is also known that drug-drug interactions can have detrimental effects, sometimes strongly decreasing the effect of a remedy. It is therefore important to separate whenever possible the active compounds eliciting the beneficial from the toxic compounds. Finally, because TCM use wild plants, the availability, quality and stability of raw material are variable and often limited (Chan, 1995). Furthermore, some of these plants are rare or threatened with extinction ( $\mathrm{Li}$ and Vederas, 2009). This is not a minor issue if you consider that more than 25,000 TCM herbal ingredients are prepared from more than 11,000 species of plants (Qiu, 2007). The same problem exists for ingredients of animal origin and the role of Chinese medicine in the extinction of prominent species (e.g. rhinoceros, tiger etc.) has often been highlighted (Graham-Rowe, 2011). If one can identify efficient and synthesizable compounds, then it would be useful for the protection of plants and biodiversity and also benefits human beings. These considerations on TCMs can also be applied to other traditional medicines that use mixtures, mostly of herbal origins. It is actually an important aim of ethnobotany to identify these complex relationships between human cultures and the medical use of plants.

The modernization of TCMs is not only to search for single compounds but also to evaluate the synergistic mechanisms of composite formulae. Therefore, an "easternization" of western medicine may 


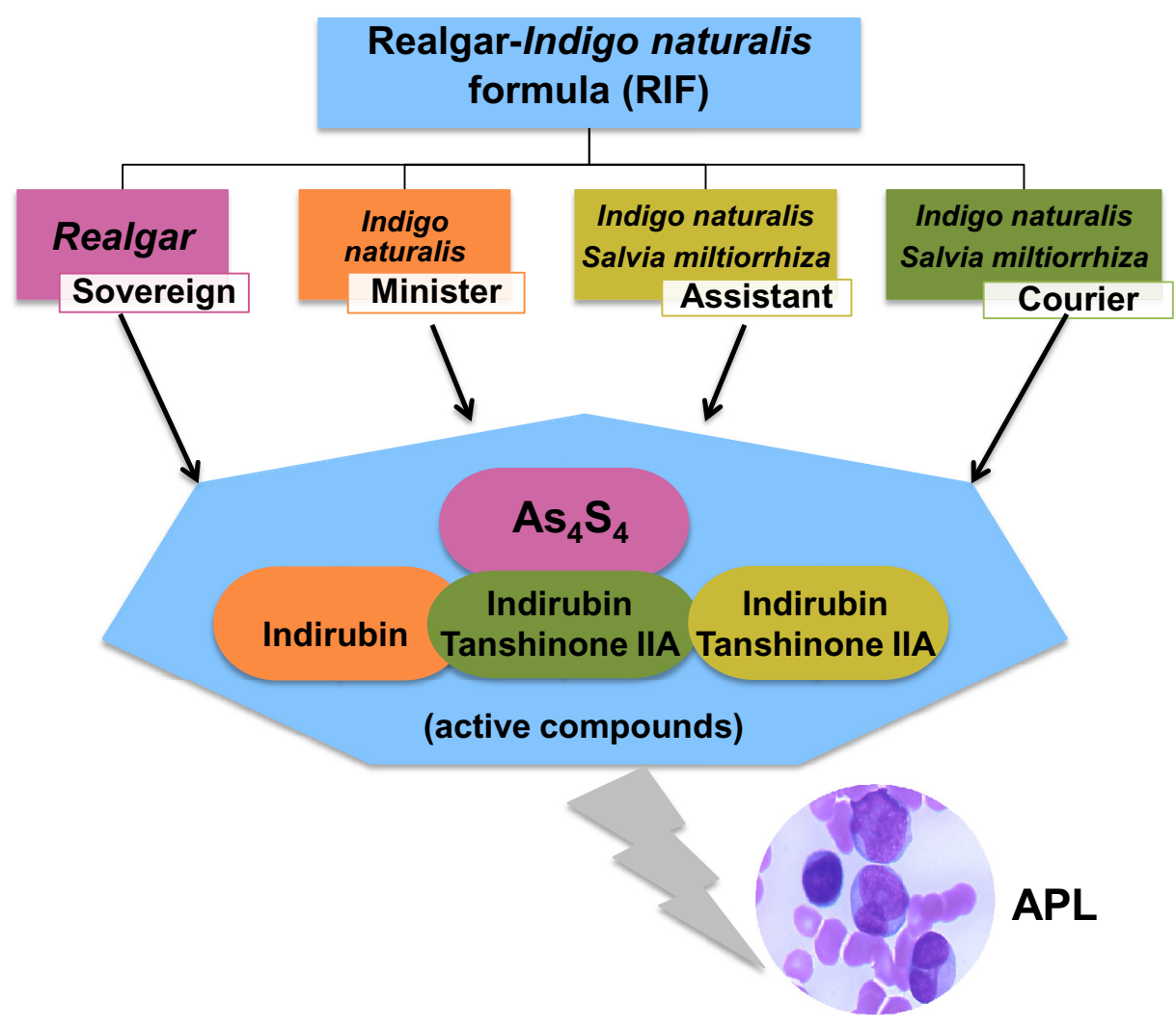

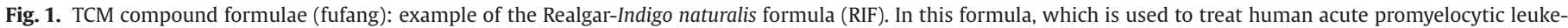

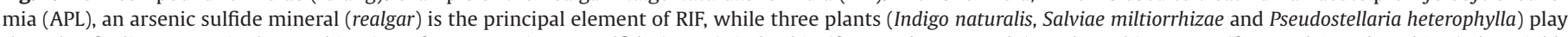

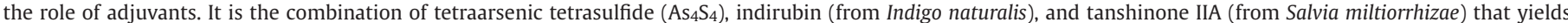

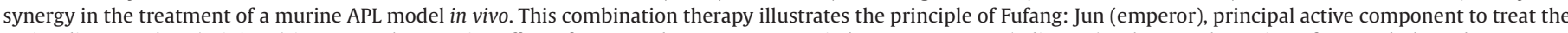

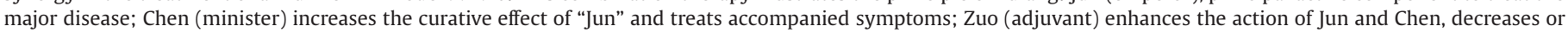
eliminates possible toxicity of the Jun and Chen, also treats accompanied symptoms; Shi (courier) coordinates the drug actions of prescription.

help to discover new drug-drug interactions for the treatment of diseases (Chan, 1995; Li and Zhang, 2008).

\section{Why study the effects of TCM on nuclear receptors?}

For all the reasons presented above, there is an urgent need to better understand what are the active compounds explaining TCM effects and to know their molecular targets in the cells. Since members of the nuclear receptor (NR) family are regulated by lipophilic molecules derived from diet and the environment, they occupy a major position in drug discovery (Gronemeyer et al., 2004) and are obvious targets for at least some TCM compounds.

Nuclear receptors are transcription factors regulated by small lipophilic ligands, such as steroid hormones, thyroid hormones, retinoids, vitamin $\mathrm{D}$ or fatty acids. Natural ligands are unknown for several NR, while others are probably true orphans (Benoit et al., 2006). The family of NRs is divided into seven subfamilies (Nuclear Receptors Nomenclature Committee, 1999). The human genome contains 48 functional NR genes, encoding more than 70 proteins (Robinson-Rechavi et al., 2001; Zhang et al., 2004). Nuclear receptors are involved in a considerable diversity of developmental and physiological processes of animals (Evans and Mangelsdorf, 2014). These modular proteins are organized into four to five regions from the $\mathrm{N}$-terminal to the $\mathrm{C}$-terminal end. The regions $\mathrm{A} / \mathrm{B}, \mathrm{D}$, and $\mathrm{F}$, not all present in all receptors, are usually poorly conserved and their structure is unknown. By contrast, the DNA-binding domain (DBD, region $C$ ) and the ligand-binding domain (LBD, region $\mathrm{E}$ ) are highly conserved and their structures have been determined for several receptors (Huang et al., 2010).
The DBD is made up of two zinc-finger structures (C4-zinc fingers), with each zinc atom being necessary to retain stable domain structure and function (Khorasanizadeh and Rastinejad, 2001). Usually NRs bind to the regulatory regions of target genes as homodimers or heterodimers with one peculiar member of the family, RXR, more rarely as monomers. Genomic studies have shown that the number of NR binding sites range from several hundreds (Gauhar et al., 2009) to several thousands (Cheung and Kraus, 2010). The canonical hormone response element (HRE) has the core sequence RGGTCA (Laudet and Gronemeyer, 2002). Mutations, extensions, duplications and distinct relative orientations of repeats of this motif generate response elements that are selective for a given class of receptor.

The ligand-binding domain (LBD) is composed of $10-12 \alpha$-helices that form three antiparallel helical layers that combine to make a $\alpha$-helical sandwich. The orientation of helix H12 controls the activity of the receptor (Billas and Moras, 2013). The LBD fulfills three main functions: ligand binding, dimerization and recruitment of coregulators. The unliganded LBD (apo conformation) undergoes a conformational change upon ligand binding (holo conformation), allowing the interaction with coactivators and the transactivation of target genes. Within the LBD, a ligand-binding pocket (LBP) contains key amino acids that interact specifically with the ligand and determines its affinity. The LBD is a domain responsible for an allosteric modification of the receptor allowing the exchange between corepressor and coactivator protein complexes associated with the basal transcription machinery (Billas and Moras, 2013; Perissi and Rosenfeld, 2005). In the absence of ligand, many NRs actively repress transcription through direct interactions with corepressors (NcoR, 
SMRT...) that recruit high molecular weight complexes with histone deacetylase activity (Perissi et al., 2010). Deacetylated histones are associated with a condensed chromatin configuration that leads to transcriptional repression. Ligand binding induces a conformational change, with a repositioning of helix $\mathrm{H} 12$, which results in the replacement of corepressors by coactivators (SRC1, TIF2/SRC2, ACTR/SRC3...). Several dozens of proteins have been described as NR co-activators, highlighting the vast array of diverse, precise and dynamic responses that can be generated (Lonard and O'Malley, 2012; Perissi and Rosenfeld, 2005). In this synthesis, it is important to note that distinct class of ligands can induce different conformation of NR LBDs. Indeed, binding of an agonist triggers a mechanism by which helix H12 is stabilized in the active conformation, thereby creating a surface of interaction with the coactivators. Conversely, binding of an antagonist keeps helix $\mathrm{H} 12$ in an inactive position. In presence of some particular antagonists called "inverse agonists", co-repressors can bind to the same surface as the co-activators, therefore displacing $\mathrm{H} 12$ from the active orientation. Beside these cases where the ligand is viewed as a simple switch, partial agonists provide only a partial activation of the NR (Huang et al., 2010). The LBP is thus a highly adaptive structure, since different ligands can induce slightly different conformations of helix $\mathrm{H} 12$, thereby generating different surfaces of interaction with regulatory complexes (Perissi and Rosenfeld, 2005). This plasticity is at the basis of the effects of ligands called selective nuclear receptor modulators (SNuRMs) because they have cell or tissue specific activities (Billas and Moras, 2013; Burris et al., 2013; Gronemeyer et al., 2004). It is important to keep in mind this huge amount of variation when studying the effects of the diverse molecules that are used in TCMs.

During the last decade, some NRs were identified as biological targets of active compounds contained in herbal remedies of TCM (Lazar, 2004). We aim to review here this expanding literature by focusing on the informative articles regarding the mechanisms of action. The meeting of TCM with NR should bring mutual benefits. First, knowledge of the molecular mode of action of a natural product will allow chemists to improve affinity, specificity, pharmacokinetics, and stability of this therapeutic compound (Corson and Crews, 2007). Some Chinese medical herbs have been used in clinical controlled trials, such as Glycyrrhizae uralensis (Gan Cao) or Salvia miltiorrhiza (Dan Shen) (Liu et al., 2013b; Wang et al., 2013), but similar tests are not available for most of them (Chan, 1995). Second, if NRs are direct targets of TCM herbal remedies, then it might provide new insights into pharmacology of these proteins. Indeed, TCM may be the source of new ligands, new modulators and even perhaps new mechanisms of action.

\section{Methodology and overview}

A search for studies on NR and TCM was conducted using PubMed and Web of Science with a combination of the terms "nuclear receptor" and "traditional Chinese medicine/herbal", as well as specific names for different NR and TCM compounds. Additional references were found manually in articles identified with the general search. We discarded articles related to food supplement. Although we focused on Chinese herbal practices, we have added, when relevant, a few good examples from other traditional medicines. Most articles were published in English, but we also analyzed 13 articles written in Chinese, therefore allowing access to these results for non-Chinese speakers.

We have selected articles that give clear experimental evidences on the mechanisms of action of TCM and their compounds. More precisely, our aim was to identify agonists and antagonists for NRs that play a functional role in the biological activity of Chinese herbal treatments. We will use the term "agonist" for a molecule that activates the transcriptional activity of an NR and produces a physiological response, while an antagonist interferes with the action of the agonist. According to this relatively wide definition, some "activating" molecules will be called agonists even if their ability to bind to the receptor is still unknown, which is often the case. Ideally, evidences from direct binding tests and crystal structure analysis are required to firmly define agonists and antagonists. Indeed, it is well known that other mechanisms than ligand binding can modulate the activation of NRs, such as post-translational modifications, protein interactions, nuclear translocation or the chromatin state at target sites (Gronemeyer et al., 2004). On the other hand, we did not select articles reporting TCM effects solely at the level of gene expression (mRNA or protein), as frequently found in clinical studies. Indeed, such effects may be indirect and, mutually, the absence of an effect at the gene expression level does not imply that the NR is not involved in the biological response.

In the search of relationships between NR and TCM pharmacology, the first obvious task is to test whether a TCM herbal treatment has an effect on an NR pathway (Table 1).

The second aim is to identify the plant extracts and the compound(s) responsible for the effects (the structures of these compounds are given in the Supplementary Fig. 1). Then one should determine whether these compounds act directly or indirectly through the modulation of the transcriptional activity of a given NR. We analyzed more than 120 articles that report significant results regarding these three steps (Supplementary Table 1). All the articles were available up to November 2013. The most frequently tested mechanisms of action are ligand binding, coregulator recruitment and nuclear translocation. By contrast, experiments on dimerization, post-translational modifications or DNA binding on the regulatory region of target genes are scarce. The overall analysis reveals a strong heterogeneity of the data, with a lot of data for a few receptors (ER, GR, AR, PPAR, PXR), a few for others (RXR, VDR, NGF-1B, NURR1) and nothing for almost half of human NRs (Table 2). The most studied NRs in relation to TCM are steroid receptors (section 4), to the exclusion of MR and PR. Then come all the NRs that regulate metabolic homeostasis and detoxication (section 5). These metabolic receptors form heterodimers with RXR, for which a rich set of structural data is available (section 6). Not surprisingly, the orphan receptors have been relatively understudied, except two real orphans of the NR4A group (section 7). From these examples, in the last section we will draw a parallel between TCMs and several non-drug compounds such as phytoestrogens or endocrine disrupting chemicals also acting via NR. Using this comparison, we will then define common principle of action and highlight the potential and limits of those compounds.

\section{Steroid receptors (NR3)}

In a chapter dedicated to the effects of TCM on steroid receptors, a special attention should be given to ginseng. Indeed, extracts of this plant can modulate ER, GR and AR activities (Li et al., 2006, 2009b). There are seven major species of ginseng, including Panax ginseng, Panax quinquefolius and Panax notoginseng. The roots of these plants are used for more than 2000 years in China, and more recently in the West, for their tonic and restorative properties. Indeed, it has been shown that ginseng compounds can increase the production of NO in the endothelium of the lung, heart, kidney, and penis (corpus cavernosum), which improve concentration, stress resistance, physical performance and sexual stamina (Attele et al., 1999). Most pharmacological effects of ginseng are attributed to ginsenosides, which are triterpene saponins found exclusively in the plant genus Panax. These compounds (more than 30) have estrogenlike and glucocorticoid-like activities. For some of them $(\operatorname{Rg} 1, \operatorname{Re})$, these properties have been explained by their ability to modulate the function of steroid receptors. 
Table 1

Main TCM plants and their major compounds discussed in the text. (For their medical use, see: http://www.tcmwiki.com/ and http://www.herbwisdom.com/).

\begin{tabular}{|c|c|c|c|c|}
\hline Latin name & Chinese name & Plant part & Compound & NR \\
\hline Angelica sinensis & Dang Gui (当归) & Root & N-butylidenephthalide (BP) & NGFI-B \\
\hline Ganoderma lucidum & Ling Zhi (灵芝) & Carpophore & Ergosterol peroxide, ganodermanontriol & FXR \\
\hline \multirow[t]{2}{*}{ Ginkgo biloba } & Yin Xing (银杏) & Seed & Quercetin, kaempferol & CAR, PXR \\
\hline & & & Ginkgolides A and B & PXR \\
\hline Glycyrrhizae uralensis & Gan Cao (甘草) & Root & Liquiritigenin & ER \\
\hline Inula japonica & Xuan Fu Hua (旋覆花) & Flower & Bigelovin & RXR \\
\hline Magnolia officinalis & Hou Po (厚朴) & Bark and flower buds & Honokiol & PPAR \\
\hline Momordica charantia & Ku Gua (苦瓜) & Fruit & $\begin{array}{l}\text { 9c, 11t, 13t-conjugated linolenic acid, DMC ( } 3 \text { beta,7 } \\
\text { beta -dihydroxy-25-methoxycucurbita-5,23-diene-19-al) }\end{array}$ & PPAR \\
\hline Panax ginseng & Ren Shen (人参) & Root, leaves & Ginsenosides (Rg1, Re, Rb1) & ER, GR \\
\hline Panax notoginseng & San Qi (三七) & Root & Dammarane-type saponins & FXR, LXR \\
\hline Psoralea corylifolia & Bu Gu Zhi (补骨脂) & Seed & Bakuchiol & ER \\
\hline Pueraria lobata & Ge Gen (葛根) & Root & Puerarin & ER \\
\hline \multirow[t]{2}{*}{ Rheum palmatum } & Da Huang (大黄) & Root & Rhein & LXR, RXR \\
\hline & & & Danthron & RXR \\
\hline Rhizoma drynariae & Gu Sui Bu (骨碎补) & Root & Naringin, naringenin & ER \\
\hline \multirow[t]{3}{*}{ Salvia miltiorrhiza } & Dan Shen (丹参) & Root & Cryptotanshinone & AR \\
\hline & & & Tanshinone IIA & PPAR \\
\hline & & & Rosmarinic acid, salvianolic acid B & FXR, LXR \\
\hline Schisandra chinensis & Wu Wei Zi (五味子) & Fruit seed & Schisandrols A and B, Schisandrins A and B & PXR \\
\hline Tithonia diversifolia & Zhong Bing Ju (肿柄菊) & Leaves & Tirotundin, tagitinin A & PPAR \\
\hline Tripterygium wilfordii & Lei Gong Teng (雷公藤) & Root & Celastrol, triptolide & AR \\
\hline Venenum Bufonis & Chan Su (蟾酥) & Venom & Bufalin & VDR \\
\hline
\end{tabular}

\subsection{Estrogen receptor (ER; NR3A)}

Estrogens are steroid hormones that play central roles in the development and maintenance of the reproductive, cardiovascular and central nervous systems. In human, two receptors, ER $\alpha$ (NR3A1) and ER $\beta$ (NR3A2), are able to bind the most potent estrogen, $17 \beta$ estradiol. Both receptors are associated with cancers and numerous diseases, such as osteoporosis (Heldring et al., 2007). They are major pharmaceutical targets and anti-estrogens such as tamoxifen have saved the life of thousands of patients with breast cancer. Different studies allowed the identification of a vast variety of phytoestrogens, which are non-steroid plant-derived chemicals, such as the isoflavone genistein found in soy. Phytoestrogens may have potential protective effects against breast and prostate cancer, and are sometimes used for the treatment of menopausal symptoms and osteoporosis, although the benefits of those practices are still debated

Table 2

TCM effects (Activation/Inhibition) on NR.

\begin{tabular}{|c|c|c|c|c|c|c|}
\hline Group & Name & Pharmacology & Activity & TCM & Active component & Reference $^{\mathrm{a}}$ \\
\hline $1 \mathrm{~A}$ & TR & Endocrine/Metabolic & - & & & \\
\hline 1B & RAR & Endocrine/Metabolic & A & Buzhong Yiqi & n-hexadecanoic acid & (Chen et al., 2010) \\
\hline \multirow[t]{3}{*}{$1 C$} & PPAR & Metabolic & A & Gynostemma pentaphyllum & Gypenoside XLIX & (Huang et al. 2007) \\
\hline & & & A & Citrus aurantium & Naringenin & (Liu et al., 2008a) \\
\hline & & & I & Danshen & Tanshinone IIA & (Gong et al., 2009) \\
\hline 1D & REVERB & Orphan & - & & & \\
\hline $1 \mathrm{~F}$ & ROR & Metabolic & - & & & \\
\hline \multirow[t]{3}{*}{$1 \mathrm{H}$} & LXR & Metabolic & I & Rheum palmatum & Rhein & (Sheng et al., 2011) \\
\hline & FXR & Metabolic & A & Ganoderma lucidum & lanostanes triterpenes & (Grienke et al., 2011) \\
\hline & & & I & Various TCM & oleanolic acid & (Liu and Wong, 2010) \\
\hline \multirow[t]{3}{*}{$1 \mathrm{I}$} & VDR & Endocrine/Metabolic & A & Ch'an Su & Bufalin & (Nakano et al., 2005) \\
\hline & PXR & Metabolic & A & Danshen & Tanshinone IIA & (Yu et al., 2009) \\
\hline & CAR & Metabolic & A & Yin Zhi Huang & 6,7-dimethylesculetin & (Huang et al. 2004) \\
\hline $2 \mathrm{~A}$ & HNF4 & Metabolic & I & Xiao-Chai-Hu-Tang & Extract of HD-1S & (Tseng et al. 2010) \\
\hline $2 B$ & RXR & Metabolic & I & Rhubarb & Danthron & (Zhang et al., 2011c) \\
\hline $2 C$ & TR2, TR4 & Orphan & - & & & \\
\hline $2 \mathrm{E}$ & TLX, PNR & Orphan & - & & & \\
\hline $2 \mathrm{~F}$ & COUP-TF & Orphan & - & & & \\
\hline \multirow[t]{3}{*}{$3 \mathrm{~A}$} & ER & Endocrine & A & Rhizoma drynariae & Naringenin & (Guo et al., 2011) \\
\hline & & & A & Panax ginseng & Ginsenoside Rg1 & (Wu et al., 2012b) \\
\hline & & & I & Tripterygium wilfordii & Triptolide & (Liu et al., 2009) \\
\hline $3 B$ & ERR & Metabolic & A & Scutellaria baicalensis & Baicalin & (Zhang et al. 2011d) \\
\hline \multirow[t]{5}{*}{$3 C$} & GR & Endocrine & A & Panax ginseng & Ginsenoside Rg1 & (Leung et al., 2006b; Wu et al., 2012b) \\
\hline & & & I & Paeoniae Rubra Radix & PGG, NPF & (Juan et al., 2011) \\
\hline & MR & Endocrine & - & & & \\
\hline & PR & Endocrine & - & & & \\
\hline & AR & Endocrine & I & Tripterygium wilfordii Hook & Celastrol, Triptolide & (Huang et al., 2012) \\
\hline \multirow[t]{2}{*}{$4 \mathrm{~A}$} & NGFIB & Orphan & A & Antiaris toxicaria & Toxicarioside D & (Jiang et al., 2008) \\
\hline & NURR1 & Orphan & A & Bushen Huoxue Decoction & Decoction & (Yang et al. 2011) \\
\hline $5 \mathrm{~A}$ & SF1, LRH1 & Orphan & - & & & \\
\hline $6 \mathrm{~A}$ & GCNF1 & Orphan & - & & & \\
\hline $\mathrm{OB}$ & DAX1, SHP & Orphan & - & & & \\
\hline
\end{tabular}

a For a full list, see Table S1 in supplementary data. 
(Chang et al., 2013; Cos et al., 2003). However, they may also act as endocrine disrupters, which could affect development and reproduction. It is therefore important to characterize the ability of a phytoestrogen to bind to the ERs. This can be done using various in vitro (Mueller, 2002) and in vivo tests (Diel et al., 2002).

Surveys of compounds present in traditional medicines used for women's health (pregnancy, childbirth, menstruation, and menopause) can provide interesting leads. For example, the evaluation of 48 plants used to treat women in the Q'eqchi Maya population in Guatemala, allowed the identification of 7 extracts that have the ability to bind to ER $\alpha$ and/or ER $\beta$ (Michel et al., 2007). Antiestrogenic effects of plant extracts have been found in TCM and in other traditional medicines, such as in Africa (Benie and Thieulant, 2003). However, their putative antagonists for ER have not been identified (Li et al., 2008; Liu et al., 2009; Lu and Cai, 2008; Onogi et al., 2006; Zhang and Ma, 2010), or their mechanisms of action are unknown, as in the case of triptolide (Liu et al., 2009). Many other plants of Chinese pharmacopoeia have low estrogenic activities (Zhang et al., 2005), sometimes in an ER-independent manner (Hao et al., 2009; Ma et al., 2010). More frequently, the estrogenic action of Chinese herbal medicines allowed extracting new phytoestrogens that are able to activate ERs, such as bakuchiol and ginsenoside Rg1 (Fig. 2 and Supplementary Table 1). Bakuchiol is a meroterpene phenol extracted from the seeds of Psoralea corylifolia, which are used to treat osteoporosis. This estrogenic component activates both ER subtypes, with a stronger binding affinity for ER $\alpha$ than for ER $\beta$ (Lim et al., 2009; Xin et al., 2010). Another example of agonist is the ginsenoside $\operatorname{Rg} 1$, a triterpenoid steroidal saponin extracted from ginseng. Although this compound has ER dependent estrogen-like activity, contradictory results were obtained regarding its ability to bind to ERs. Competitive binding assay in MCF-7 cell lysates could not detect interaction of Rg1 with estrogen receptors at low concentrations (nanomolar) (Chan et al., 2002), whereas it was found to bind ER $\alpha$ with low affinity at higher concentrations (micromolar) (Wu et al., 2012b). Results from docking simulation suggest that
Rg1 can mimic 17ß-estradiol into the ER $\alpha$ LBD (Wu et al., 2012b). The neuroprotective activity of $\mathrm{Rg} 1$ in primary rat cerebrocortical neurons involves an increase in the nuclear translocation of ER $\alpha$, but not ER $\beta$ (Wu et al., 2012b).

Estrogens have an intrinsic duality, showing either protective or pathogenic effects in various diseases (Ahmed et al., 2014). Similarly, phytoestrogens that bind to ERs can produce an anti-estrogenic effect by competing with $17 \beta$-estradiol. As an example, puerarin can promote the recruitment of corepressors to ER $\alpha$ as well as limiting the recruitment of coactivators in endometriotic stromal cells (Ji et al., 2013). Similar effects have been observed with the flavonoid naringin and its active metabolite naringenin, two compounds extracted from Rhizoma drynariae (Gusuibu), a TCM plant used to treat osteoporosis. Both agonists show weak estrogenic activity at low concentration and bind more to ER $\beta$ than to ER $\alpha$ in yeast twohybrid assay (Guo et al., 2011; Kuiper et al., 1998). Interestingly, at high concentration, or when there are too many endogenous estrogens, these compounds could exhibit antagonist activity, suggesting that they behave as partial agonists. It has been shown that naringenin binding induces depalmitoylation of ER $\alpha$, which impairs its association with the plasma membrane, thereby reducing the non-genomic activation of this receptor (Galluzzo et al., 2008). The dual opposite effects of naringenin and naringin, depending on their amount relative to the endogenous ligand may be useful for the treatment of osteoporosis (Guo et al., 2011).

An important issue in using hormone therapy to control menopausal symptoms is to have selective estrogen-receptor modulator (SERM) at one's disposal. The action of these compounds on ER is different in various tissues (Lonard and Smith, 2002). For example, tamoxifen acts as an antagonist in breast and as an agonist in uterus. The effects of SERM are explained by selective recruitment of coactivators (agonism) or co-repressors (antagonism) and also because the two subtypes ER $\alpha$ and ER $\beta$ have partially different patterns of expression. Most of the ER agonists identified in TCM have a dual action on both ER $\alpha$ and ER $\beta$, but preferentially activate or bind one

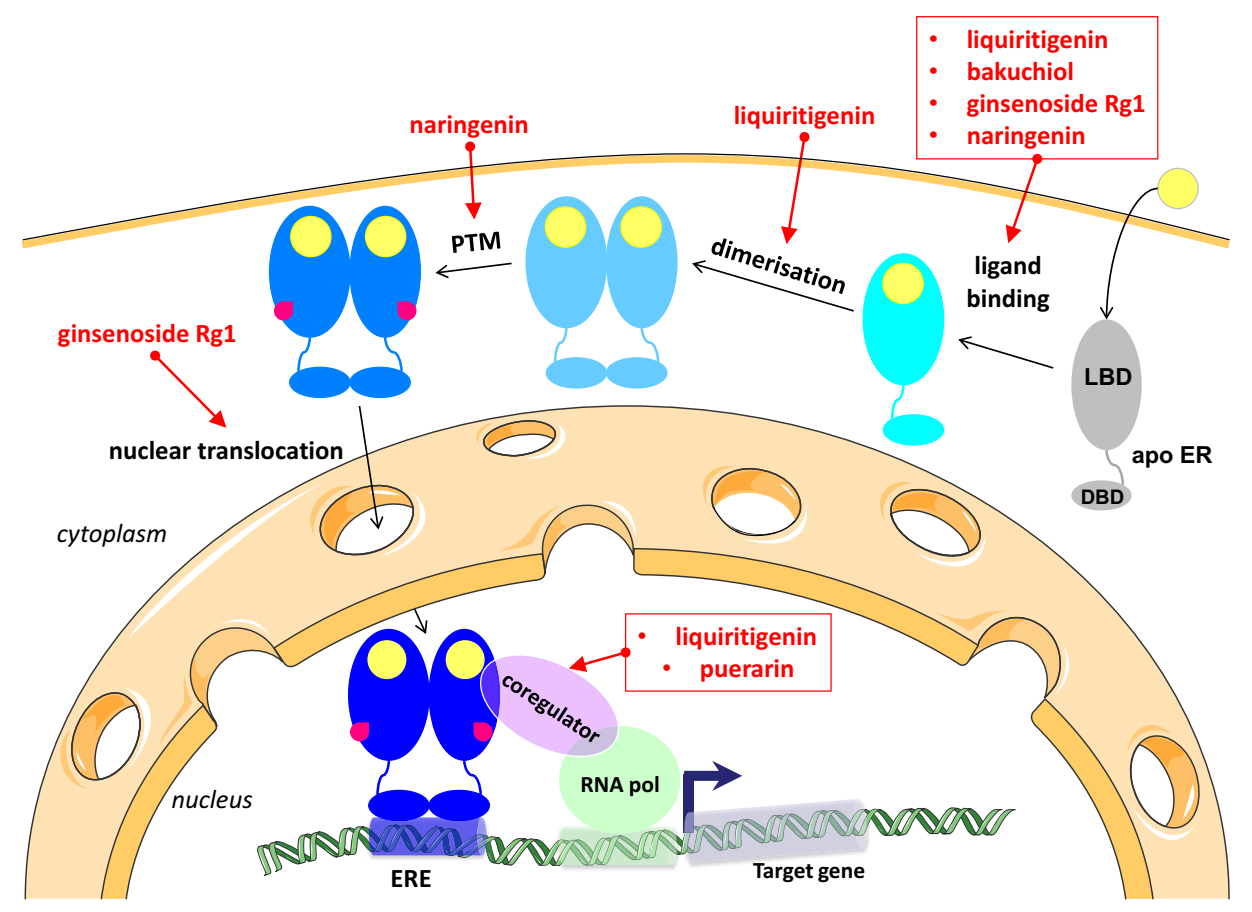

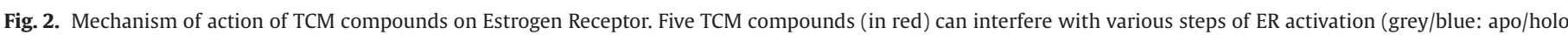

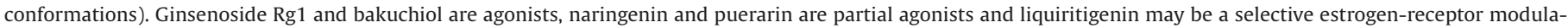

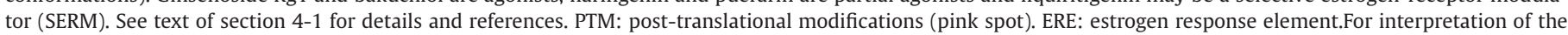
references to color in this figure legend, the reader is referred to the web version of this article. 
of them, suggesting that they may effectively behave as SERMs (Fan et al., 2009; Guo et al., 2011; Ji et al., 2013; Liu et al., 2012; Xin et al., 2010). Up to now, this hypothesis has only been confirmed for the flavanone liquiritigenin, the most active estrogenic compound from licorice root (Glycyrrhizae uralensis), which is present in the TCM formula MF101, an ethanol/aqueous extract of 22 herbs used for the treatment of vasomotor symptoms (Cvoro et al., 2007). Liquiritigenin is a poorer structural mimic of estradiol than isoflavonoids such as genistein. Competition binding, FRET and limited proteolysis assays have shown that liquiritigenin binds to ER $\beta$ with a 20 fold higher affinity than to $\mathrm{ER} \alpha$ (Mersereau et al., 2008). Liquiritigenin activated only ER $\beta$ pathways in human cancer cell lines and is able to induce ER $\beta$ homodimerization and $\mathrm{ER} \alpha / \beta$ heterodimerization, but not ER $\alpha$ homodimerization (Powell and Xu, 2008). Furthermore, ChIP experiments revealed that the ER $\beta$-liquiritigenin complex is competent for selective recruitment of coactivators and for binding to regulatory chromatin sites of estrogen-responsive genes (Jiang et al., 2013; Mersereau et al., 2008).

It has been proposed that improving the treatment of postmenopausal women will probably require to combine a SERM with conjugated estrogens, a therapy which has been described as a tissue selective estrogen complex (Pickar et al., 2010). In our perspective, it is thus relevant to note that future therapies may meet the ancient tradition of Chinese medicine, where the combination of drugs is a major concept and practice.

\subsection{Glucocorticoid receptor (GR; NR3C1)}

The glucocorticoid receptor (GR) plays important developmental and physiological roles, associated with metabolic, cardiovascular and immune disorders. In addition, glucocorticoids are regulators of stress response with positive effects associated to the mobilization of attention and resources linked to acute stress and the more negative side with deficits in attention and learning, as well as metabolic and immunological anomalies associated with chronic stress (Frank et al., 2013).

One putative GR antagonist has been identified from the roots of Paeonia lactiflora, an anti-diabetic medicine (Juan et al., 2011). Several active compounds of ginseng are also agonists of GR, such as the ginsenosides Re (Leung et al., 2007a), compound K (Yang et al., 2008a) and Rg1 (Li, 2004). Competitive ligand-binding assay and transactivation experiments have shown that ginsenoside Rg1 is a functional ligand of GR with an estimated Kd one to three orders of magnitude lower than that of dexamethasone, the most powerful synthetic agonist of this receptor (Chung et al., 1998; Lee et al., 1997; Leung et al., 2006a; Wu et al., 2012b). Modeling the docking of ginsenoside Rg1 to the structure of human GR LBD confirmed these results (Leung et al., 2006a). The biological activities of ginsenoside $\operatorname{Rg} 1$ in vitro are apparently mediated by an increase in the phosphorylation of the PI3K/Akt pathway, both in rodents' neurons (Leung et al., 2007b; Wu et al., 2013) and in human umbilical vein cells (Cheung et al., 2011; Leung et al., 2006a, 2006b). These neuronal and angiogenic effects of $\operatorname{Rg} 1$ are dependent on an increase in GR phosphorylation and on an induction of nuclear translocation of the phosphorylated GR (Du et al., 2011; Leung et al., 2006a; Wu et al., 2012b). Interestingly, as mentioned above, $\operatorname{Rg} 1$ is also an agonist of ERs, clearly showing that individual compounds present in TCMs can bind to several receptors (Fig. 3), a notion that has already been shown for endocrine disruptors, another class of compounds that exhibit complex and multiform action via NRs (see Concluding section).

As a TCM, ginseng contains many other active compounds in addition to the ginsenoside $\mathrm{Rg} 1$. It is thus interesting to compare the effects of Rg1 with those of GSS, an extract of stem and leaves of Panax ginseng, which contains a mixture of ginsenosides $(20.88 \%$ Rg1, 18.5\% Re, 5.66\% Rb1, 2.38\% Rb2) (Ling et al., 2005). Although GSS alone does not change the levels of GR, it can reverse the glucocorticoid-induced effects, both in vitro (Ling et al., 2005) and

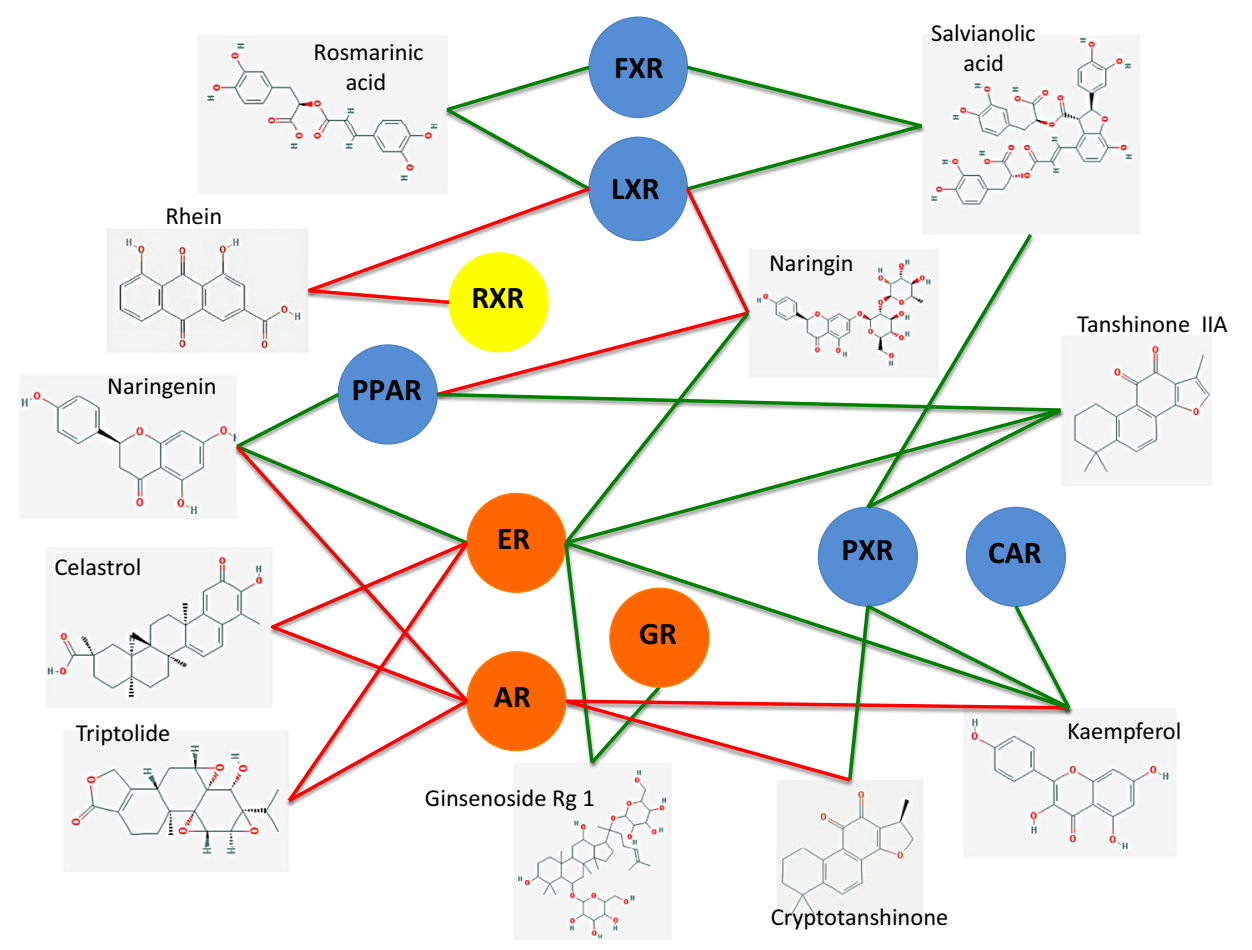

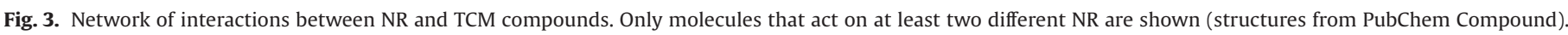

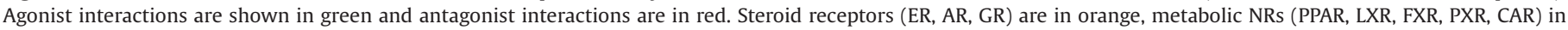

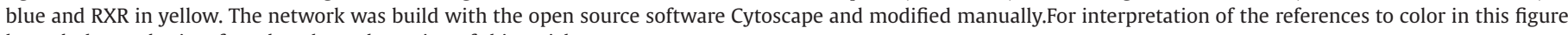
legend, the reader is referred to the web version of this article. 
in vivo (Binbin et al., 2009). Indeed, an increase in GR expression level and GR hormone binding capacity is observed when human normal liver cells or rats are co-treated with GSS and glucocorticoid. Furthermore, GSS increases GR translocation in the liver of rats (Binbin et al., 2009). The authors conclude that the activity of ginsenoside $\operatorname{Rg} 1$ is stronger than that of a ginseng extract that contains other ginsenosides. Since both treatments show glucocorticoid activity, it suggests that other compounds present in ginseng may display antagonist effects on GR and may therefore be the source of interesting new compounds yet to be discovered.

An important aim in steroid pharmacology is the identification of "dissociated" compounds that would allow separation between the GR transactivation and the cross talk mediated by other transcription factors, such as AP-1 or NF-kappaB. An interesting case of such dissociated compound has been described (De Bosscher et al., 2005). The Compound A (2-(4-acetoxyphenyl) 2-chloro-Nmethylethylammonium-chloride) is a phenyl aziridine precursor derived from the Namibian shrub Salsola tuberculatiformis that is used by bushmans as an effective oral contraceptive. This compound inhibits adrenal steroidogenesis and acts as a contraceptive (Swart et al., 2003). It is also able to compete with dexamethasone for binding to GR with an IC50 in the nanomolar range. Further studies revealed that compound A exerts an antiinflammatory potential by down-regulating proinflammatory genes, such as IL-6, but was unable to enhance GRE-driven target genes, nor to induce GR binding to GREs-containing promoters in vivo (De Bosscher et al., $2005,2014)$. The compound A is one of the first isolated compounds displaying such a dissociated activity and therefore became a valuable pharmacological tool, if not yet an established medical treatment.

\subsection{Androgen receptor $(A R ; N R 3 C 4)$}

The androgen receptor (AR) is involved in the development of male sexual characteristics, as well as in the physiology of female reproductive system (Chang et al., 2013). This receptor has been associated with prostate cancer, sexual abnormalities (including sexual impotence) and is a major target for molecules used in doping (Ahmed et al., 2014; Cooper et al., 2013). Since the proliferation of prostate cancer cells are strictly dependent on androgens, an important therapeutic strategy against this pathology is to use antagonists for AR such as flutamide. Although the current data suggest that some TCM preparations contain putative antagonist or agonist for AR, their mechanisms of action are usually unknown (Gauthaman and Adaikan, 2005; Han et al., 2007; Yang et al., 2008b). However, interesting pharmacological results have been obtained with two Chinese medicinal herbs: Lei Gong Teng (Tripterygium wilfordii) and Danshen (Salvia miltiorrhiza).

Two terpenes extracted from the root bark of Tripterygium wilfordii (Lei Gong Teng or Thunder of God Vine), celastrol and triptolide, can inhibit cell growth and induce cell death through an inhibition of the proteasome. These effects are AR-dependent and both compounds can decrease the expression of AR and suppress its transcriptional activity in androgen-sensitive human prostate adenocarcinoma cells (Huang et al., 2012; Yang et al., 2006). More information is available on the mechanisms of action of cryptotanshinone, a terpene found in the roots of Danshen. This compound possesses a variety of biological effects, including the ability to inhibit prostate cancer cell growth in vitro and in vivo (Wu et al., 2012a; Xu et al., 2012; Zhang et al., 2012). The anti-tumoral effects of cryptotanshinone are explained, at least in part, by selective inhibition of the dihydrotestosterone-induced AR transactivation, which results in the inhibition of the AR target genes expression (Wu et al., 2012a; Xu et al., 2012; Zhang et al., 2012). These results are apparently not due to the inhibition of either AR protein expression, or AR protein nuclear translocation (Wu et al., 2012a; Xu et al., 2012), although a minor down-regulation of these processes might play a role (Zhang et al., 2012). It was recently revealed that the antiandrogen activity of cryptotanshinone is mediated by inhibition of AR dimerization and of the AR-coregulator complex formation (Xu et al., 2012). Furthermore, cryptotanshinone disrupts the interaction between activated AR and lysine-specific demethylase 1 on chromatin, which inhibits histone H3 lysine 9 (H3K9) demethylation, resulting in the inhibition of AR target genes (Wu et al., 2012a). Although these results suggest than cryptotanshinone could be a ligand for AR, its binding affinity to this receptor is actually very weak (Xu et al., 2012; Zhang et al., 2012). It seems therefore that cryptotanshinone is likely not a direct antagonist for AR, and its mode of action needs further analysis.

These examples show that TCM active compounds can target the androgen-signaling pathway at different points around AR. This is exactly what is needed to develop new therapies that can bypass hormonal resistance. More generally, we may expect that the characterization of such complex mode of action of compounds present in TCMs will provide new tools and ideas for both clinical and basic science.

\section{Metabolic receptors}

Metabolic NRs act as nutritional sensors that regulate metabolic homeostasis and detoxication. Members of this functional group are all adopted orphan receptors, which means that they were primarily discovered as orphan receptors and later on shown to be liganded (Chawla et al., 2001; Evans and Mangelsdorf, 2014). Their ligands are fatty acids or cholesterol metabolites that are dietary products, intermediate metabolites or xenobiotics. These ligands bind to the receptor with low affinities (micromolar range of concentration) to large LBPs that can accommodate a large diversity of compounds (Benoit et al., 2004). Because of these differences with hormonal receptors, the metabolic members of the NR family are often described as "sensors" (Sladek, 2010). The idea is that the physiological role of these receptors is to finely tune the metabolic network by sensing the relative amounts of key compounds of this network (Blumberg et al., 1998). Another difference with steroid receptors is that these NRs generally bind to DNA as heterodimers with the retinoid X receptor (RXR) on specific HREs organized in direct repeats (Desvergne, 2007). However, this is not specific to these sensors as classical receptors such as TRs or RARs behave similarly.

\subsection{Peroxisome proliferator activated receptor (PPAR; NR1C)}

Activation of PPARs proteins (PPAR $\alpha$, PPAR $\beta / \delta$ and PPAR $\gamma$ ) in the digestive system or in the adipose tissues regulates fatty acid metabolism (storage or usage, depending of the activated PPAR) and controls energy homeostasis. These receptors are implicated in diseases such as obesity, type II diabetes (non insulin dependent) and atherosclerosis. Several TCMs used to treat these diseases can increase the expression of PPARs genes both in vitro and in vivo (Supplementary Table 1) (Huang et al., 2005). In a few cases, transactivation tests revealed that some TCM formulae or their compounds behave as agonists of PPAR $\alpha$ (Huang and Hong, 2006; Huang et al., 2006), PPAR $\gamma$ (Liu et al., 2008b; Suk et al., 2008; Zhou et al., 2009) or both (Chuang et al., 2006; Lin, 2012; Liu et al., 2008a). As an example, honokiol, a compound isolated from magnolia bark, binds directly to PPAR $\gamma$ LBD and acts as a partial agonist (Atanasov et al., 2013). Honokiol is a clinically interesting compound because it can prevent hyperglycemia and weight gain in mice. Another interesting case is cinnamomi cortex, a compound isolated from the Japanese traditional medicine Hachimi-jio-gan, which is used to improve several metabolic disorders such as diabetes. This molecule activates PPAR $\alpha$, but not PPAR $\gamma$ (Monden et al., 2008). The most thorough study identified two agonists from Tithonia diversifolia, a 
plant used in Chinese medicine to treat diabetes and hepatitis. After extraction, two sesquiterpene lactones, tirotundin and tagitinin A, showed an ability to activate both PPAR $\alpha$ and PPAR $\gamma$ in transactivation assays. Furthermore, it was shown that the two compounds bind directly to PPAR $\gamma$ LBD with affinities in the micromolar range. Finally, docking simulations revealed that the binding modes of tirotundin and tagitinin A to PPAR $\gamma$ LBD were similar to the known agonist aleglitazar (Lin, 2012). These results identified tirotundin and tagitinin A as PPAR $\alpha / \gamma$ dual agonists that might be useful to treat diabetes with less cardiovascular side effects that the current drugs. Indeed, the complementary action of simultaneous activation of each PPAR in patients suffering from metabolic syndrome and type 2 diabetes (PPAR $\alpha$ agonist improving dyslipidemia and PPAR $\gamma$ agonists improving insulin resistance and diabetes) has led to new pharmacological strategies focused on the development of agonists targeting more than one receptor such as the dual PPAR $\alpha / \gamma$ agonists (Rubenstrunk et al., 2007). This is exactly what tirotundin and tagitinin A are doing, as well as other compounds found in Indian Ayurvedic medicine (Yang et al., 2013). These results provide a direct example in which paradigms of traditional medicines and western medicine effectively meet.

Also noteworthy are the results obtained by a Taiwanese group working on the wild bitter gourd Momordica charantia. This vegetable is commonly used as a medicinal treatment in Asia, Africa, and South America because of its anti-diabetic, antibacterial, antiviral, and chemopreventive functions. Extracts of bitter gourd are able to activate PPAR $\alpha$ and PPAR $\gamma$ in vitro (Chao and Huang, 2003) and in vivo (Chao et al., 2011). Further purifications identified the active compounds (9c, 11t, 13t-conjugated linolenic acid), which are able to activate PPAR $\alpha$ (Chuang et al., 2006). Another compound isolated from this plant exhibit anticancer effects through activation

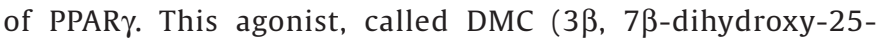
methoxycucurbita-5,23-diene-19-al), is a cucurbitane-type triterpene that induces the death of human breast cancer cells. In cultured cancer cells, DMC does not alter the expression level of PPAR $\gamma$ protein but instead facilitates its nuclear localization in a manner similar to that of known agonists. Furthermore, DMC suppresses the expression of PPAR $\gamma$ target genes associated with proliferation and apoptosis (Weng et al., 2013).

An unresolved paradox is that both agonists and antagonists of PPAR $\gamma$ can apparently protect against obesity and diabetes type 2 . This has been confirmed by the identification of a natural antagonist of PPAR $\gamma$ from Danshen (Salvia miltiorrhiza), which is widely used to treat cardiovascular disease in TCM. The most abundant ingredient of Danshen is Tanshinone IIA, a lipophilic diterpene that binds to PPAR $\gamma$ LBD (120 times less than the PPAR $\gamma$-specific agonist rosiglitazone) and reduces PPAR $\gamma$ transcriptional activity (Gong et al., 2009). The down-regulation of PPAR $\gamma$ target genes by tanshinone IIA led to an improvement of glucose tolerance and a reduction of body weight in obese mice. This apparent paradox may be explained by the dual nature of PPARs transcription factors as either activators or inhibitors of their target genes.

\subsection{Liver $X$ receptor and farnesoid $X$ receptor (LXR, FXR; NR1H)}

Both LXR and FXR are major regulators of cholesterol and bile acid homeostasis. In addition, they also modulate fatty acid and glucose metabolism. LXR $\alpha$ (NR1H3) and LXR $\beta$ (NR1H2) are sensors for oxysterols such as 22(R)-hydroxycholesterol or cholestenoic acid, whereas FXR is recognized by a wide variety of bile acids, among which chenodeoxycholic acid (Calkin and Tontonoz, 2012). Note that the human genome contains one functional FXR gene (FXR $\alpha$; NR1H4) and one FXR pseudogene (FXR $\beta$;NR1H5). Several TCMs used to treat hyperlipidemia, obesity and related metabolic disorders have been tested for their effects on these NRs. These efforts led to the discovery of putative agonists and antagonists for FXR and LXR (Fig. 4). Given the current interest in these receptors for drug discovery, TCM

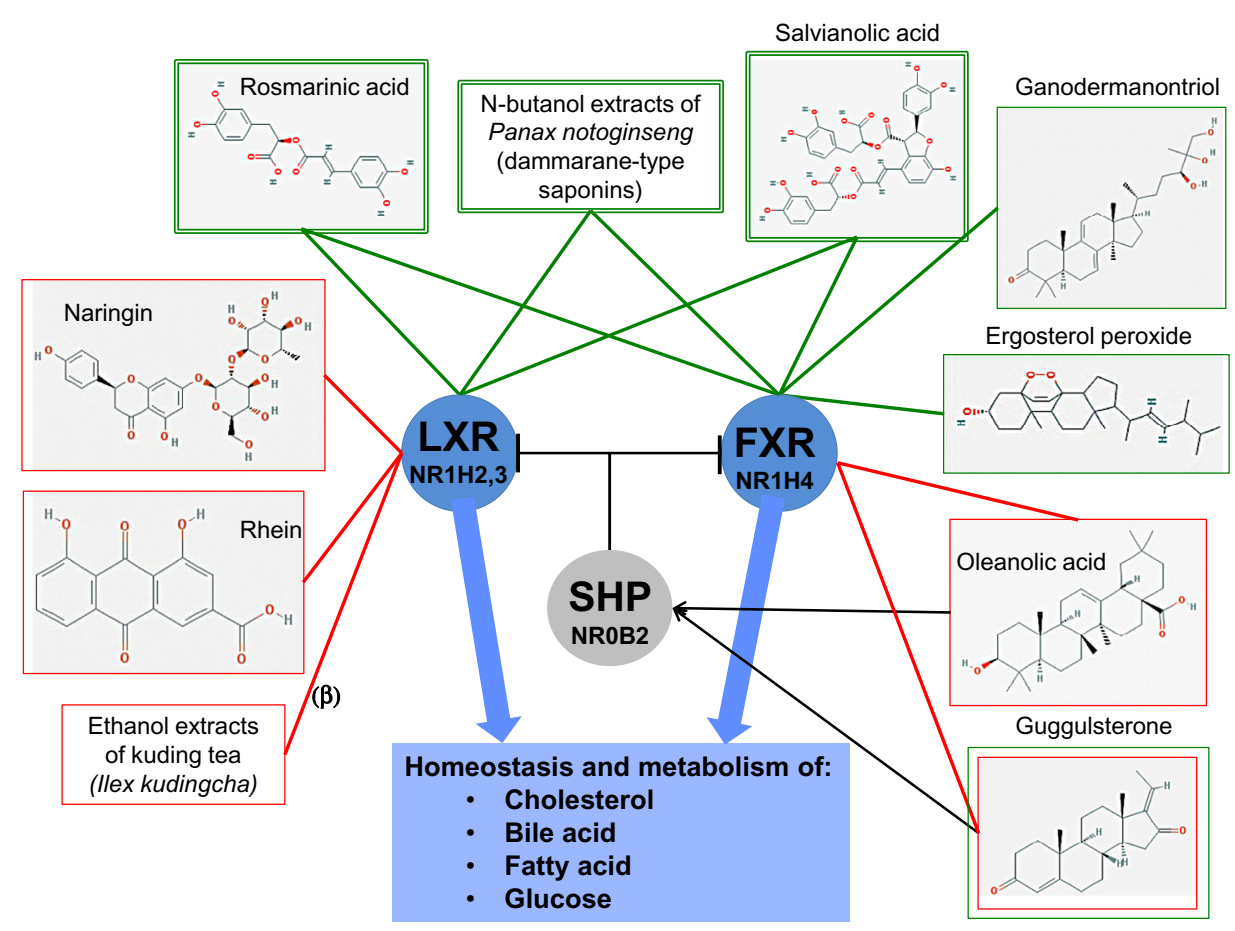

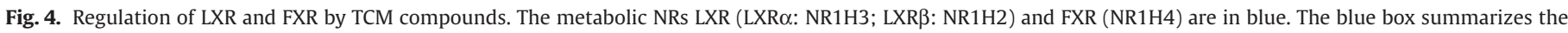

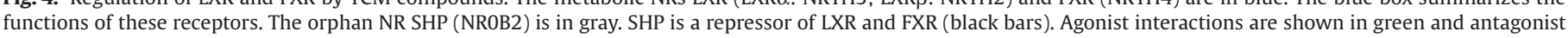

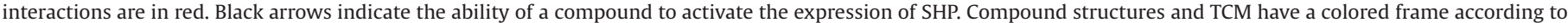

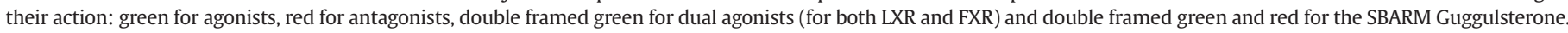

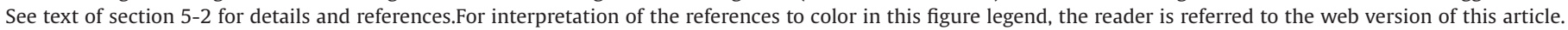


should be viewed as a very valuable source of new and promising compounds (Cariou and Staels, 2007).

Virtual screening of a Chinese herbal medicine database with structure-based pharmacophore models revealed lanostane-type triterpenes of the fungus Ganoderma lucidum (lingzhi) as putative FXR agonist ligands. Activation of FXR occurred at micromolar range in a gene reporter assay and docking of the most active compounds, ergosterol peroxide and ganodermanontriol, into human FXR revealed their putative binding mode (Grienke et al., 2011). Since FXR and LXR act in the same metabolic pathways and are activated by various classes of steroids, we might expect that some compounds could interact with the two receptors. Currently, the only known dual agonist is the synthetic molecule TC0901317 (Houck et al., 2004). Interestingly, using a GAL4 transactivation assay, the extracts of two different TCM also showed a dual agonistic activity on both FXR and LXR $\alpha$ (Ji and Gong, 2007, 2008). These two coagonists are n-butanol extract of Panax notoginseng, which contains dammarane-type saponins, and purified Salvia miltiorrhiza extract, which main active compounds are salvianolic acid B and rosmarinic acid. Both medicines prevent the accumulation of abnormal lipid in hyperlipidemic rats. Furthermore, the n-butanol extract of Panax notoginseng can induce LXR $\alpha$ and FXR target genes in liver (Ji and Gong, 2007). Once again, the use of TCM can lead to the emergence of new class of compounds that may be of great interest for current development in drug discovery.

Putative antagonists of NR1H were also identified from TCM (Fig. 4). For example, rhein, an anthraquinone extracted from Rheum palmatum, can suppress the transcriptional activity of both LXR $\alpha$ and LXR $\beta$ in a gene reporter assay (Sheng et al., 2011). By contrast, ethanol extract of kuding tea (Ilex kudingcha) has a specific antagonist action on LXR $\beta$, but not on LXR $\alpha$ (Fan et al., 2012). Regarding FXR, oleanolic acid, a triterpenoid contained in various Chinese medicine used to treat liver disease, can suppress the activity of FXR without changing its level of expression. This inhibition can be explained by the fact that, in vitro, oleanolic acid can bind to the LBD of FXR and block its ability to interact with the coactivator SRC-3 (Liu and Wong, 2010). In addition, oleanolic acid can induce the expression of SHP (small heterodimer protein), a peculiar NR with no DBD (NROB). Since SHP is the heterodimeric partner and repressor of various NRs, the repressive effects of some TCM on FXR may be mediated by SHP. It has been suggested that oleanolic acid is a selective bile acid receptor modulator (SBARM). This concept could also be applied to guggulsterone, a plant sterol found in the exudates produced by the bark of Commiphora species, or myrrh (Mo Yao). The therapeutic effects of myrrh have been discovered in India, where Ayurvedic medicine use extracts of the gum resin of the guggul tree (Commiphora mukul, guggulu in Sanskrit) for almost 3000 years (Shen et al., 2012). Many other indigenous medicines, including in China, use this resin for the treatment of pain, arthritis, parasitic infection, gastrointestinal diseases and obesity. Guggulsterone, which lower lowdensity lipoprotein cholesterol levels in humans, is able to block the interactions between FXR and its coactivators, thereby acting as an antagonist for this receptor (Urizar et al., 2002; Wu et al., 2002). Surprisingly, guggulsterone is also able to enhance the action of agonists on a subset of FXR target genes (SHP, BSEP) (Cui et al., 2003). The structural basis of this activity was partially elucidated by modeling and hydrogen/deuterium exchange mass spectrometry, which revealed a non-canonical mode of interaction for guggulsterone (Meyer et al., 2005; Yang et al., 2014). This peculiar ability of gene selective modulation indicates that the low affinity ligand guggulsterone is a selective bile acid receptor modulator.

\subsection{Xenobiotic receptors (PXR, CAR; NR1I)}

Pregnane X receptor (PXR; NR1I3) and constitutive androstane receptor (CAR; NR1I2) are well known sensors that activate the expression of the phase I and phase II exogenous xenobiotic metabolizing enzymes and transporters (Willson and Kliewer, 2002). They can bind to a wide range of ligands, including endogenous molecules such as oxysterols and bile acids (PXR) or androgen metabolites (CAR). A distinctive feature of PXR is the large dimension of its LBP (apo volume: $1300 \AA^{3}$ ), which can adjust its shape to ligands of different size (Moore et al., 2006). Important target genes of these receptors encode proteins of the cytochrome P450 superfamily (CYP), the main effectors of these xenobiotic clearance pathways. One of these enzymes, the hepatic monooxygenase CYP3A4, is involved in the oxidation of an enormous range of substrates, including approximately half the drugs that are used today (Wang et al., 2012b). Thus, if one drug activates PXR or CAR, it may induce cytochrome P450 enzymes, resulting in a reduction of the efficacy of the treatment or even in the production of toxic side effects. That is why PXR and CAR have been considered as molecular targets to predict herb-drug interactions (Kakizaki et al., 2009). More recently, it has been shown that PXR and CAR are also involved in glucose and lipid metabolism, as well as the pathogenesis of metabolic diseases (Gao and Xie, 2012). All these functions related to detoxification and elimination of xenobiotics and endobiotics are ensured by the expression of both PXR and CAR in the gastrointestinal system (stomach, intestine, gall bladder) and liver.

It is difficult to detect agonists for CAR in cell-based assays because this receptor possesses a high level of constitutive activity. However, transfection assays in human primary hepatocyte have revealed that the flavonoids quercetin and kaempferol are able to activate both CAR and PXR (Li et al., 2009a). By contrast, many herbs used in TCM have the ability to activate PXR in human liver cell lines. Most of the tests analyze a single plant or remedy, but larger screens have been made recently (Liu et al., 2011; Yu et al., 2011). These efforts led to the isolation of an array of agonists that can modulate different functions of PXR: ligand binding (Lau et al., 2012; Moore et al., 2000), DNA binding (Wang et al., 2012b) or recruitment of coactivators (Lichti-Kaiser and Staudinger, 2008). One of the first cases of interaction between a herbal medicine and a NR was actually identified by studying the dangerous herb-drug interactions induced by St. John's wort (Hypericum perforatum). This plant is commonly used all over the northern hemisphere (Chinese name: Guan Ye Lian Qiao) for the treatment of depression, but it increases the metabolism of various drugs (contraceptives, antivirals, immunosuppressants). Hyperforin, a constituent of St. John's wort's extracts, is a potent agonist for PXR, which regulates CYP3A4 in primary human hepatocytes (Moore et al., 2000). The crystal structure of hyperforin in complex with the LBD of human PXR revealed conformational changes and increase in the size of the LBP (Watkins et al., 2003). These results suggest that PXR evolved as part of the body's defense mechanism against potentially toxic ingested plant products. As a second example, the ginkgolides A and B from Ginkgo biloba extracts can activate PXR in cell-based reporter gene assays (Lau et al., 2012; Li et al., 2009a). This activation occurs through direct binding of the compounds to the LBD of PXR. The two ginkgolides recruit steroid receptor coactivator-1 (SRC-1) to human PXR and increase the expression of the target gene CYP3A4 (Lau et al., 2012). Interestingly, these effects are receptor-selective, since these compounds are not able to activate CAR, which regulates CYP3A4. Furthermore, other structurally related ginkgolides have no effect on the two xenobiotic receptors. This example illustrates the complexity of the underlying molecular mechanisms that govern the regulation of NRs by TCM drugs.

Despite the identification of almost 30 agonists, the crystal structures of TCM compounds bound to PXR or CAR LBD are still not available (except for hyperforin-PXR, not specific to TCM). Molecular docking analysis is usually coherent with the experimental data showing ligand activation, but they cannot provide the real mode of action (Lau et al., 2012; Liu et al., 2011). Further structural studies are particularly important in the case of PXR, which is 
characterized by a large and flexible LBP that can bind to a wide range of exogenous compounds (Moore et al., 2006). Furthermore, both PXR and CAR LBD exhibit high sequence divergence between species. It is indeed well known that potent agonists for human PXR or CAR (such as rifampicin or CITCO, respectively) are inactive against murine homologs. This interspecific variability is even used to study ligand activation in humanized transgenic mouse expressing the human PXR or CAR instead of the endogenous receptor. Such mice can respond only to appropriate human agonists (Huang et al., 2011; Lichti-Kaiser and Staudinger, 2008). Nevertheless, it is possible to investigate the structural determinants of ligand binding to an NR by using site-directed mutagenesis. This strategy has been used to understand the species-specific activation of PXR by Wu Wei Zi (Schisandra chinensis) and its constituents, Schisandrols A and B and Schisandrins A and B (Mu et al., 2006). Rat and human PXR differ at an amino acid located near the entry of the LBP (rat F305/human L308). The mutation F305L in the rat PXR had no effect on activation by Wu Wei $\mathrm{Zi}$ extracts and Schisandrol $\mathrm{A}$ and Schisandrin A. However, it increased activation by Schisandrol B and decreased activation by Schisandrin B. By contrast, the reciprocal mutation in human PXR (L308F) completely abolished its activation by either the Wu Wei Zi extract or its constituents. Therefore, mutations at a single position in the LBP of PXR had speciesspecific effects on the activities of the individual Schisandrols and Schisandrins.

As expected for pleiotropic receptors, several compounds present in TCM formulae can activate PXR and CAR. Future investigations on these agonists may reveal if they play a role in the complex interactions that occur between drugs and herbal treatments.

\section{Retinoid X receptor (RXR; NR2B)}

The retinoid $\mathrm{X}$ receptors ( $\mathrm{RXR} \alpha, \beta, \gamma$; NR2B1, 2,3 ) are master regulators that bind to a wide range of ligands. The endogenous ligand was first proposed to be 9-cis-retinoic acid (Allenby et al., 1993) (Fig. 5A,B), but it has been impossible to prove with certainty that this compound is a natural ligand for RXR. Later, this status was also given to fatty acids, such as phytanic acid (Kitareewan et al., 1996; Lemotte et al., 1996) or docosahexaenoic acid (DHA) (de Urquiza et al., 2000). Surprisingly, this controversial issue remains unsolved (Germain et al., 2006). There is a very rich set of structural data for RXR LBD (apo or holo), with all types of conformations: monomer, homodimer, heterodimer and tetramer. A major feature of RXR is its ability to form heterodimers with many NRs (TR, RAR, VDR, NURR1, NGFI-B), including the metabolic receptors described in section 5 (PPAR, LXR, FXR, PXR, CAR). The three RXR genes are expressed in almost every tissues and, consequently, they are known to play a role in many different biological functions (development, reproduction, metabolism, immunity, etc.) and diseases (Dawson and Xia, 2012). Despite this central position in the NR pathways, the modulation of RXR by TCM has received little attention. Fortunately, the group of Shen Xu in Shanghai performed detailed structural analysis of the interaction between RXR and three different compounds isolated from two plants (Fig. 5).

\section{A 9cis-Retinoic Acid (3D)}

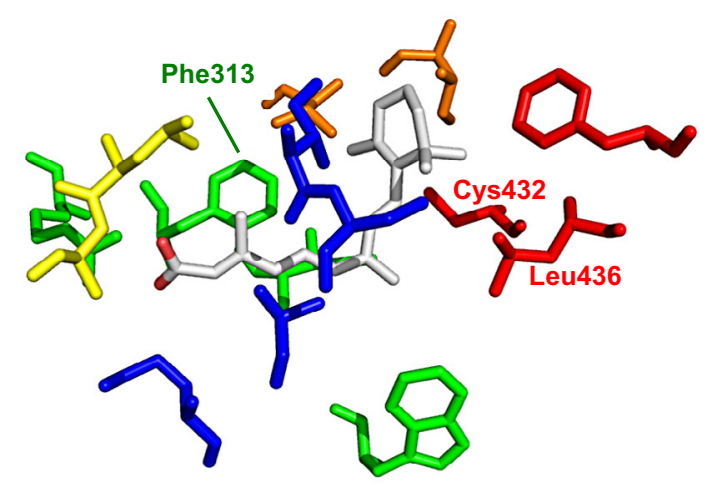

C rhein

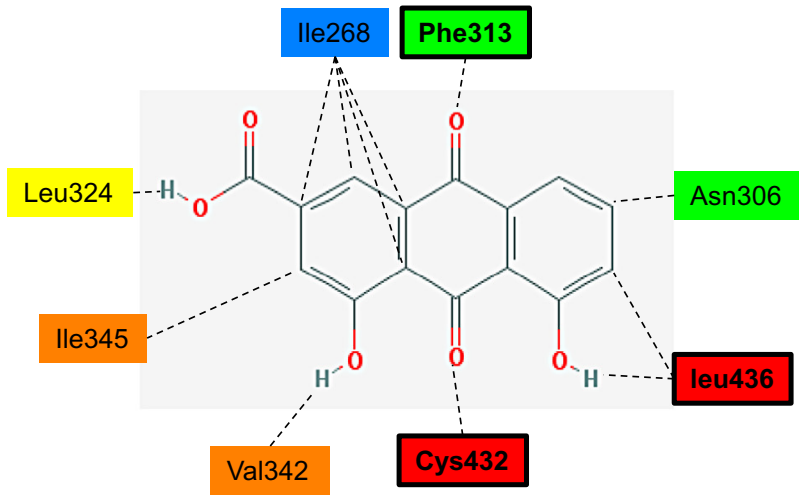

\section{B 9cis-Retinoic Acid}

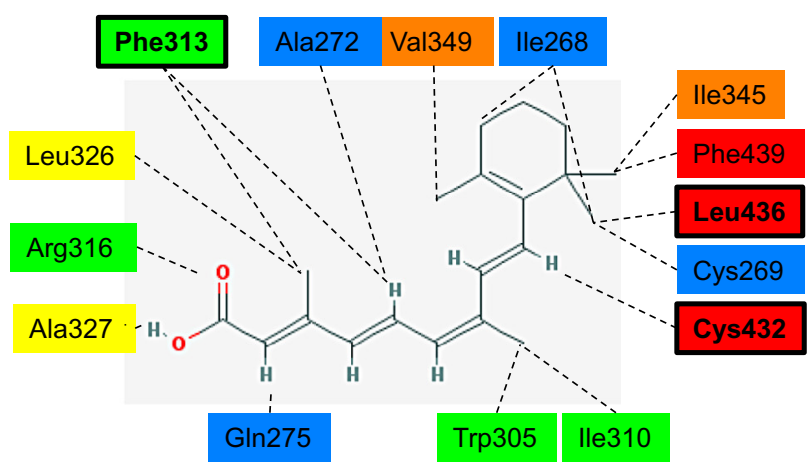

D bigelovin

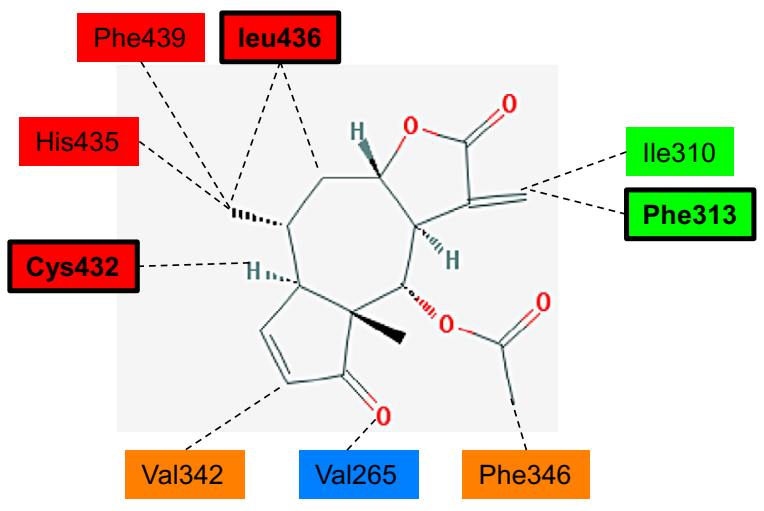

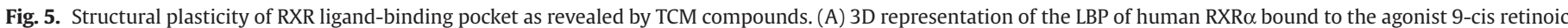

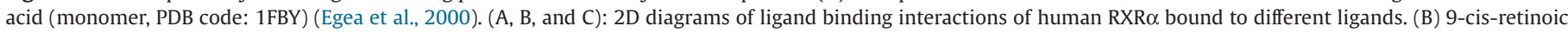

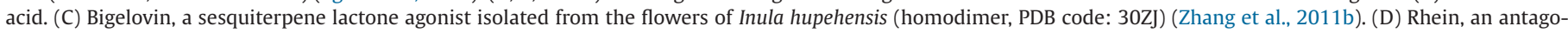

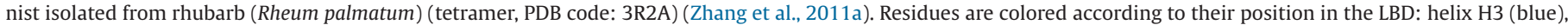

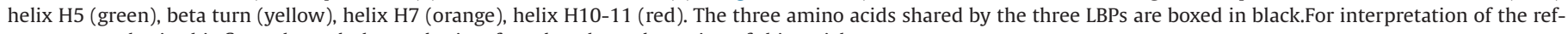
erences to color in this figure legend, the reader is referred to the web version of this article. 
Two antagonists (danthron and rhein) were isolated from rhubarb (Rheum palmatum), a plant with antidiabetic and anticancer properties (Zhang et al., 2011a, 2011c). These two anthraquinones, which differ by one carboxyl group, can bind selectively to human RXR $\alpha$ (Fig. 5C) and inhibit the transactivation by RXR homodimer and RXR heterodimers with PPAR, LXR and FXR. The structural analysis revealed that both danthron and rhein stabilizes the RXR tetramer, which is the major apo form of RXR that dissociates in presence of agonist. They also induce a displacement of the corepressor SMRT2. Surprisingly, rhein behaves as an antagonist on RXRa-LXRa heterodimer but has no effect on LXRa alone (Zhang et al., 2011a). Another team reported that rhein could suppress the transcriptional activity of both $\mathrm{LXR} \alpha$ and LXR $\beta$ alone in a gene reporter assay (Sheng et al., 2011). These contradictory results could be explained by the antagonistic action of rhein on RXR. This illustrates the necessity to take RXR into account when considering the effects of a given ligand on a heterodimeric partner. The same group of Shen $\mathrm{Xu}$ in Shanghai discovered that the sesquiterpene lactone bigelovin, extracted from Inula hupehensis flowers, is a selective agonist for RXR (Zhang et al., 2011b) (Fig. 5D). Bigelovin enhances transactivation of the RXR $\alpha$-PPAR $\gamma$ heterodimer on PPRE and represses RXR $\alpha$ LXR $\alpha$ on LXRE, but had no effect on RXR homodimer or on the RXR $\alpha$ FXR heterodimer. The crystal structure of bigelovin-activated RXR $\alpha$ LBD homodimer shows that binding of this ligand alters the conformation of helix $\mathrm{H} 10$, which constitutes the core of the dimerization interface (Zhang et al., 2011b). This result is very interesting, because it might explain the selectivity on the permissive heterodimers with PPAR and LXR.

The availability of crystal structures remains an exception in the study of TCM-NR interactions. The RXR example shows how structural data can bring important insights to better understand the mechanisms of action of TCM.

\section{Other nuclear receptors}

\subsection{Vitamin D receptor (VDR; NR1I1)}

In contrast with the two other members of the NR1I group (PXR and CAR), the vitamin D3 receptor (VDR) is a highly specific NR. The natural ligand of VDR is calcitriol (1,25 dihydroxyvitamin D3), a steroid hormone that is well known for its role in calcium homeostasis. Bile acids can also, in certain conditions, act as VDR ligands (Makishima et al., 2002). In addition, VDR controls cell growth and differentiation and is associated with cancer, cardiovascular pathologies, growth defects and a wide range of disorders affecting homeostasis and metabolism of different systems (immune, nervous, reproductive, renal/urinary, skeleton) (Laudet and Gronemeyer, 2002). The effects of TCM on VDR are currently unknown, except for bufalin, an inhibitor of sodium pump isolated from toad venom (Chan Su). The group of Makishima Makoto, in Japan, found that bufalin couldn't bind directly to VDR (Nakano et al., 2005). However, it is an indirect enhancer of VDR activity through several mechanisms such as modulation of coactivator recruitment, histone acetylation at VDR target site and increased nuclear vitamin D3-induced VDR expression in nucleus (Amano et al., 2009). Although bufalin is not a real agonist for VDR, this example shows how TCM can help to identify molecules that modulate the activity of NR in a ligand-independent manner. It is expected that such molecules may enhance therapeutic effects of calcitriol or minimize its side effects. We find again the Chinese concept of combining molecules to obtain better drugs.

\subsection{Real orphan receptors (NGF-1B/NUR77; NURR1; NR4A)}

In human, the NR4A subfamily contains three proteins (NGFI-B or NUR77: NR4A1; NURR1: NR4A2; NOR1: NR4A3) that are considered as real orphan because they act as constitutive transcription factors.
Indeed, it has been shown that both NURR1 (HR38 in Drosophila) and NGFI-B lack an LBP (Baker et al., 2003; Flaig et al., 2005; Wang et al., 2003). As such, these orphan receptors might be seen as less interesting for pharmacological studies. However, since all members of NR4A subfamily are immediate-early genes whose expression is induced by various stress stimuli and growth factors, they could easily be viewed as targets of other molecules. It is also known that the heterodimers that NURR1 and NGFI-B form with RXR are responsive to specific RXR ligands (Pearen and Muscat, 2010).

A few studies analyzed the effects of TCM on NGFI-B (also called NUR77), because this orphan receptor mediates apoptotic signaling in cancer cells (Chen et al., 2008; Jiang et al., 2008; Lin et al., 2008; Liu et al., 2013a). The natural compound $\mathrm{N}$-butylidenephthalide (BP), isolated from Angelica sinensis (danggui), can induce apoptosis of tumor cells (brain, liver), which reduce growth tumor both in vitro and in vivo. These antitumoral effects are mediated by the induction of NGFI-B expression and translocation of this protein from the nucleus to the cytoplasm, where it is targeted into mitochondria, resulting in the activation of apoptosis (Chen et al., 2008; Lin et al., 2008). These results helped to design an n-butylidenephthalide derivative ( $\mathrm{PCH} 4)$ with increased antitumoral effects. Interestingly, while BP induced NGFI-B-mediated apoptosis is dependent of AKT pathway, $\mathrm{PCH} 4$ effects are mediated by the JNK pathway. These different mechanisms may explain the increase in the anti-tumor effects (Chang et al., 2011).

Therefore, as for hormone receptors, real orphan NRs can be the target of molecules found in TCM preparations. The modulation of their activity by these compounds is probably involved in the therapeutic effects of Chinese medicines.

\section{Conclusion: when nuclear receptors meet traditional Chinese medicine}

What have we learned so far from this meeting between NRs and TCM? First, it is obvious that TCM is a wonderful source of new ligands for NRs and that a systematic screen of TCM will enrich the pharmacology of these receptors. The same strategy could be applied to other traditional herbal medicines such as those from central America (Michel et al., 2007), Africa (Mahomoodally, 2013) or Australia (Simpson et al., 2013), for example. As discussed above, several interesting compounds such as dual PPAR $\alpha / \gamma$ agonists, dissociated glucocorticoids or tissue selective estrogen complex have been described and are probably the precursor of a rich set of new molecules. Up to now, TCM has not revealed new principles for NR pharmacology since the ligands that have been characterized in TCM fall into known categories of ligands. It is likely that this situation will change in the coming years, with the characterization of more and more compounds and activities. Indeed, the emergence of alternative pharmacological principles connected to the NR family (non genomic effects, post-translational modifications, alternative ligand sites, cross-talk with other pathways) provide a rich universe to explore and to fill with specific compounds (Pawlak et al., 2012; Samarut and Rochette-Egly, 2012; Souza et al., 2014).

\subsection{Research avenues on the TCM-NR interplay}

It is clear that the exploration of TCM potential in terms of classical NR ligands is far from being complete (Table 2).

Indeed, there is a strong bias toward specific receptors such as steroid receptors (in particular ERs) as well as xenobiotic receptors and PPARs. The effects of TCM compounds on prominent NRs such as thyroid hormone receptor (TR) and retinoic acid receptor (RAR) have been largely understudied. For TR, one paper has reported a change in TR $\beta$ gene expression accompanied by its coactivators SRC1 and SRC3 in peripheral white blood cells in coldintolerant Yang-deficient constitution (Wang and Yao, 2008). This 
may be a significant observation, as the TH pathway is important for heat production. Regarding RAR, it has been shown that Pharicin $\mathrm{B}$ extracted from Isodon pharicus stabilizes RAR $\alpha$ protein and enhances ATRA-dependent transcriptional activity on RAR $\alpha$ (Gu et al., 2010). Unfortunately, apart from these quite marginal studies, TR and RAR, which are so important in terms of disease, are virtually unknown as TCM targets. This situation may be due to a historical bias, ER being one of the first NR to be studied and one for which a number of pharmacological targets and therapeutic interventions are needed. Alternatively, it may be a purely biological bias linked to the ability of the LBP of specific NRs such as ER or PXR to accommodate very different ligands, whereas others (such as RAR) are more rigid. The truth probably lies between these two extreme views but only more unbiased screens using in silico or in vitro methods will be able to better delineate the landscape of TCM action at the NR level.

Other key questions remain to be solved regarding TCM action on NRs. First, it will be very important to obtain direct evidence of binding, with 3D structures of TCM active compounds bound to NRs. Such data may bring surprises and allow to define the SNuRM properties of many TCM compounds (Gronemeyer et al., 2004). In addition, as mentioned above, we can anticipate the characterization of alternative binding sites on the surface of the receptors as it has been described for ER (Estebanez-Perpina et al., 2007; Moore et al., 2010) and TR (Souza et al., 2014). We can also hypothesize that different modes of interaction of the same compound on a given LBP will be uncovered, as it has been demonstrated for PXR (Watkins et al., 2001). Lastly, one can even found situations with different stoichiometry, such as two (or more) molecules of ligands interacting with a given NR (Rocchi et al., 2001). Therefore, the structural biology of TCM interaction via NR is certainly an important direction to follow. A second key question is that of pleiotropy. Indeed, one compound can interact with several receptors (Fig. 3). As an example, Tanshinone IIA can act via PPARs, ER, GR, PXR and CAR (Fan et al., 2009; Gong et al., 2009; Yu et al., 2009). Such a situation is extremely interesting in terms of cross talk between NR pathways and may help to define a new paradigm of NR action. Finally, transcriptomic studies should allow a better understanding of how TCM control gene regulatory networks, when compared to endogenous ligands. In particular, how do dual compounds such as Tanshinone IIA act on transcription level? The use of model organisms such as zebrafish that allow to combine transcriptomic data and specific gene knock down may help to define the specific part of the gene regulatory network regulated by such compounds that are under the control of a given activated receptor (see (Samarut et al., 2014) for an example).

\subsection{Common principles on the ligand galaxy}

As mentioned above, one basic paradigm of TCM action is the combination in a mixture of several compounds that combine the presence of an active principle with others playing synergistic functions and/or important for detoxification, treatment of side effects or helping for delivery (Tian, 2011). It should be mentioned that the issue of concentration is important to consider here, as it remains possible that, in numerous cases the concentrations of individual compounds required to modulate NR activity are not reached in the herb extracts. Indeed how the compounds are metabolized and divided in the various organs is a very complex and poorly addressed question that must be studied in more details. In addition, it is clear that synergistic effects of the various compounds present in extracts (adjuvants etc.) should also be taken into account. The transcriptomic research proposed above would be very useful to compare the effects of single compounds with those of mixtures. Indeed, it is striking how the western medicine has ignored the potential of mixtures for curing diseases. This may be partic- ularly important for the modern chronic diseases that have an increasing prevalence and that are linked to a complex interplay of causes, from genetic predisposition to lifestyle. It is now clear that diseases such as obesity, diabetes and metabolic syndrome are due to an imbalance of exquisitely complex homeostatic mechanisms that control sugar and fat levels in various parts of the body. TCM is a very interesting way of treating these diseases because it aims to restore a lost equilibrium by acting on the deregulated network of interactions with a low magnitude at multiple levels. Therefore it could be postulated that rather than simply viewing TCM as a source of molecules that should be "modernized" or "westernized", one should rather consider a reciprocal help between western and Chinese philosophy of medicine. We may benefit from an "easternization" of our current drug discovery system based on the use of highly specific single compounds as TCM may benefit from a better molecular definition of its principle of actions.

When TCM are considered globally, there is an obvious parallel that can be done with endocrine disrupting chemicals (EDC). Indeed, TCMs and EDCs might be viewed as the Ying and the Yang of the "NR ligand galaxy", to follow the "Big Bang" metaphor recently highlighted for the discovery of RXR heterodimerization (Evans and Mangelsdorf, 2014). In both TCMs and EDCs we found the same variety of mode of actions with SNuRMs activity but also pleiotropic ligands acting on different receptors. In both cases we can envisage alternative ligand interaction sites and complex stoichiometry that, in addition to the other mechanisms mentioned above will generate a very complex pharmacology. Furthermore, for both EDC and TCM there is such a continuum of effects that it is quite difficult to draw a specific line between positive and negative actions, which often depends on the context of the exposure/administration. In addition, TCM and EDCs are deeply connected to compounds linked to nutrition. For example, genistein is present in soy and can be viewed both as a TCM and as an EDC! This is probably not by chance, as we may face here the evolutionary origin of the NR family itself and its strong connection to food derived compounds from which many hormonal systems probably evolved. A synthesis between TCM and EDC will require a meeting between western and Chinese medical traditions. We therefore strongly encourage studying TCM and EDC together, and we are convinced that a deep understanding of NR action on physiology and development will emerge from such research.

\section{TCM databases}

Traditional Chinese Medicine @ Taiwan: http://tcm.cmu.edu.tw/ Traditional Chinese Medicines Integrated Database: http:// www.megabionet.org/tcmid/

\section{Acknowledgements}

We thank Frédéric Flamant, Guillaume Holzer and Shin-Ichi Nishio for reading and commenting on earlier versions of this review. Thanks to Thomas Iwema for his help in the determination of ligandbinding interactions for Fig. 5. We also thank the reviewers and editors who helped us to find the appropriate form for this nonconventional topic. Ling Li was supported by the "Joint Research Institute for Science and Society" (JORISS), French Ministry of Foreign Affairs (Eiffel scholarships) $\left(\mathrm{N}^{\circ} 783990 \mathrm{~A}\right)$ and China Scholarship Council (CSC) $\left(\mathrm{N}^{\circ} 20096141\right)$.

\section{Appendix: Supplementary material}

Supplementary data to this article can be found online at doi:10.1016/j.mce.2014.10.024. 


\section{References}

Ahmed, A., Ali, S., Sarkar, F.H., 2014. Advances in androgen receptor targeted therapy for prostate cancer. J. Cell. Physiol. 229, 271-276.

Allenby, G., Bocquel, M.T., Saunders, M., Kazmer, S., Speck, J., Rosenberger, M., et al., 1993. Retinoic acid receptors and retinoid X receptors: interactions with endogenous retinoic acids. Proc. Natl. Acad. Sci. U.S.A. 90, 30-34.

Amano, Y., Cho, Y., Matsunawa, M., Komiyama, K., Makishima, M., 2009. Increased nuclear expression and transactivation of vitamin $\mathrm{D}$ receptor by the cardiotonic steroid bufalin in human myeloid leukemia cells. J. Steroid Biochem. Mol. Biol. $114,144-151$.

Atanasov, A.G., Wang, J.N., Gu, S.P., Bu, J., Kramer, M.P., Baumgartner, L., et al., 2013. Honokiol: a non-adipogenic PPARgamma agonist from nature. Biochim. Biophys. Acta $1830,4813-4819$.

Attele, A.S., Wu, J.A., Yuan, C.S., 1999. Ginseng pharmacology: multiple constituents and multiple actions. Biochem. Pharmacol. 58, 1685-1693.

Baker, K.D., Shewchuk, L.M., Kozlova, T., Makishima, M., Hassell, A., Wisely, B., et al., 2003. The Drosophila orphan nuclear receptor DHR38 mediates an atypical ecdysteroid signaling pathway. Cell 113, 731-742.

Benie, T., Thieulant, M.L., 2003. Interaction of some traditional plant extracts with uterine oestrogen or progestin receptors. Phytother. Res. 17, 756-760.

Benoit, G., Malewicz, M., Perlmann, T., 2004. Digging deep into the pockets of orphan nuclear receptors: insights from structural studies. Trends Cell Biol. 14, 369-376.

Benoit, G., Cooney, A., Giguere, V., Ingraham, H., Lazar, M., Muscat, G., et al., 2006. International Union of Pharmacology. LXVI. Orphan nuclear receptors. Pharmacol. Rev. 58, 798-836.

Billas, I., Moras, D., 2013. Allosteric controls of nuclear receptor function in the regulation of transcription. J. Mol. Biol. 425, 2317-2329.

Binbin, C., Yinglu, F., Juan, D., Changquan, L., 2009. Upregulation effect of ginsenosides on glucocorticoid receptor in rat liver. Horm. Metab. Res. 41, 531-536.

Blumberg, B., Sabbagh, W., Jr., Juguilon, H., Bolado, J., Jr., van Meter, C.M., Ong, E.S., et al., 1998. SXR, a novel steroid and xenobiotic-sensing nuclear receptor. Genes Dev. 12, 3195-3205.

Burris, T.P., Solt, L.A., Wang, Y., Crumbley, C., Banerjee, S., Griffett, K., et al., 2013. Nuclear receptors and their selective pharmacologic modulators. Pharmacol. Rev. $65,710-778$.

Calkin, A.C., Tontonoz, P., 2012. Transcriptional integration of metabolism by the nuclear sterol-activated receptors LXR and FXR. Nat. Rev. Mol. Cell Biol. 13, 213-224.

Cariou, B., Staels, B., 2007. FXR: a promising target for the metabolic syndrome? Trends Pharmacol. Sci. 28, 236-243.

Chan, K., 1995. Progress in traditional Chinese medicine. Trends Pharmacol. Sci. 16, 182-187.

Chan, R.Y., Chen, W.F., Dong, A., Guo, D., Wong, M.S., 2002. Estrogen-like activity of ginsenoside Rg1 derived from Panax notoginseng. J. Clin. Endocrinol. Metab. 87, 3691-3695.

Chang, C., Lee, S.O., Wang, R.S., Yeh, S., Chang, T.M., 2013. Androgen receptor (AR) physiological roles in male and female reproductive systems: lessons learned from AR-knockout mice lacking AR in selective cells. Biol. Reprod. 89, 21.

Chang, L.F., Lin, P.C., Ho, L.I., Liu, P.Y., Wu, W.C., Chiang, I.P., et al., 2011. Overexpression of the orphan receptor Nur77 and its translocation induced by $\mathrm{PCH} 4$ may inhibit malignant glioma cell growth and induce cell apoptosis. J. Surg. Oncol. 103, $442-450$.

Chao, C.Y., Huang, C.J., 2003. Bitter gourd (Momordica charantia) extract activates peroxisome proliferator-activated receptors and upregulates the expression of the acyl CoA oxidase gene in H4IIEC3 hepatoma cells. J. Biomed. Sci. 10, 782-791.

Chao, C.Y., Yin, M.C., Huang, C.J., 2011. Wild bitter gourd extract up-regulates mRNA expression of PPARalpha, PPARgamma and their target genes in C57BL/6J mice. J. Ethnopharmacol. 135, 156-161.

Chawla, A., Repa, J.J., Evans, R.M., Mangelsdorf, D.J., 2001. Nuclear receptors and lipid physiology: opening the X-files. Science 294, 1866-1870.

Chen, C.Y., 2011. TCM Database@Taiwan: the world's largest traditional Chinese medicine database for drug screening in silico. PLoS ONE 6, e15939.

Chen, D.F., Li, X.C., Xu, Z.W., Liu, X.B., Du, S.H., Li, H., et al., 2010. Hexadecanoic acid from Buzhong Yiqi decoction induced proliferation of bone marrow mesenchymal stem cells. J. Med. Food 13, 967-975.

Chen, X.W., Serag, E.S., Sneed, K.B., Zhou, S.F., 2011. Herbal bioactivation, molecular targets and the toxicity relevance. Chem. Biol. Interact. 192,161-176.

Chen, Y.L., Jian, M.H., Lin, C.C., Kang, J.C., Chen, S.P., Lin, P.C., et al., 2008. The induction of orphan nuclear receptor Nur77 expression by n-butylenephthalide as pharmaceuticals on hepatocellular carcinoma cell therapy. Mol. Pharmacol. 74, 1046-1058.

Cheung, E., Kraus, W.L., 2010. Genomic analyses of hormone signaling and gene regulation. Annu. Rev. Physiol. 72, 191-218.

Cheung, L.W., Leung, K.W., Wong, C.K., Wong, R.N., Wong, A.S., 2011. Ginsenoside-Rg1 induces angiogenesis via non-genomic crosstalk of glucocorticoid receptor and fibroblast growth factor receptor-1. Cardiovasc. Res. 89, 419-425.

Chuang, C.Y., Hsu, C., Chao, C.Y., Wein, Y.S., Kuo, Y.H., Huang, C.J., 2006. Fractionation and identification of 9c, 11t, 13t-conjugated linolenic acid as an activator of PPARalpha in bitter gourd (Momordica charantia L). J. Biomed. Sci. 13, 763-772.

Chung, E., Lee, K.Y., Lee, Y.J., Lee, Y.H., Lee, S.K., 1998. Ginsenoside Rg1 down-regulates glucocorticoid receptor and displays synergistic effects with cAMP. Steroids 63, 421-424.

Cooper, E.R., McGrath, K.C., Heather, A.K., 2013. In vitro androgen bioassays as a detection method for designer androgens. Sensors (Basel) 13, 2148-2163.
Corson, T.W., Crews, C.M., 2007. Molecular understanding and modern application of traditional medicines: triumphs and trials. Cell 130, 769-774.

Cos, P., De Bruyne, T., Apers, S., Vanden Berghe, D., Pieters, L., Vlietinck, A.J., 2003 Phytoestrogens: recent developments. Planta Med. 69, 589-599.

Cui, J., Huang, L., Zhao, A., Lew, J.L., Yu, J., Sahoo, S., et al., 2003. Guggulsterone is a farnesoid $X$ receptor antagonist in coactivator association assays but acts to enhance transcription of bile salt export pump. J. Biol. Chem. 278, 10214-10220.

Cvoro, A., Paruthiyil, S., Jones, J.O., Tzagarakis-Foster, C., Clegg, N.J., Tatomer, D., et al., 2007. Selective activation of estrogen receptor-beta transcriptional pathways by an herbal extract. Endocrinology 148, 538-547.

de Urquiza, A.M., Liu, S., Sjoberg, M., Zetterstrom, R.H., Griffiths, W., Sjovall, J., et al., 2000. Docosahexaenoic acid, a ligand for the retinoid X receptor in mouse brain. Science 290, 2140-2144.

Dawson, M.I., Xia, Z., 2012. The retinoid X receptors and their ligands. Biochim. Biophys. Acta 1821, 21-56.

De Bosscher, K., Vanden Berghe, W., Beck, I.M., Van Molle, W., Hennuyer, N., Hapgood, J., et al., 2005. A fully dissociated compound of plant origin for inflammatory gene repression. Proc. Natl. Acad. Sci. U.S.A. 102, 15827-15832.

De Bosscher, K., Beck, I.M., Dejager, L., Bougarne, N., Gaigneaux, A., Chateauvieux S., et al., 2014. Selective modulation of the glucocorticoid receptor can distinguish between transrepression of NF-kappaB and AP-1. Cell. Mol. Life Sci. 71, 143163.

Desvergne, B., 2007. RXR: from partnership to leadership in metabolic regulations. Vitam. Horm. 75, 1-32.

Diel, P., Schmidt, S., Vollmer, G., 2002. In vivo test systems for the quantitative and qualitative analysis of the biological activity of phytoestrogens. J. Chromatogr. B. Analyt Technol Biomed Life Sci. 777, 191-202.

Du, J., Cheng, B., Zhu, X., Ling, C., 2011. Ginsenoside Rg1, a novel glucocorticoid receptor agonist of plant origin, maintains glucocorticoid efficacy with reduced side effects. J. Immunol. 187, 942-950.

Egea, P.F., Mitschler, A., Rochel, N., Ruff, M., Chambon, P., Moras, D., 2000. Crystal structure of the human RXRalpha ligand-binding domain bound to its natural ligand: 9-cis retinoic acid. EMBO J. 19, 2592-2601.

Estebanez-Perpina, E., Arnold, L.A., Nguyen, P., Rodrigues, E.D., Mar, E., Bateman, R. et al., 2007. A surface on the androgen receptor that allosterically regulates coactivator binding. Proc. Natl. Acad. Sci. U.S.A. 104, 16074-16079.

Evans, R.M., Mangelsdorf, D.J., 2014. Nuclear receptors, RXR, and the Big Bang. Cell $157,255-266$

Fan, G.W., Gao, X.M., Wang, H., Zhu, Y., Zhang, J., Hu, L.M., et al., 2009. The antiinflammatory activities of Tanshinone IIA, an active component of TCM, are mediated by estrogen receptor activation and inhibition of iNOS. J. Steroid Biochem. Mol. Biol. 113, 275-280.

Fan, S., Zhang, Y., Hu, N., Sun, Q., Ding, X., Li, G., et al., 2012. Extract of Kuding tea prevents high-fat diet-induced metabolic disorders in C57BL/6 mice via liver $\mathrm{X}$ receptor (LXR) beta antagonism. PLoS ONE 7, e51007.

Flaig, R., Greschik, H., Peluso-Iltis, C., Moras, D., 2005. Structural basis for the cell-specific activities of the NGFI-B and the Nurr1 ligand-binding domain. J. Biol. Chem. 280, 19250-19258.

Frank, M.G., Watkins, L.R., Maier, S.F., 2013. Stress-induced glucocorticoids as a neuroendocrine alarm signal of danger. Brain Behav. Immun. 33, 1-6.

Galluzzo, P., Ascenzi, P., Bulzomi, P., Marino, M., 2008. The nutritional flavanone naringenin triggers antiestrogenic effects by regulating estrogen receptor alpha-palmitoylation. Endocrinology 149, 2567-2575.

Gao, J., Xie, W., 2012. Targeting xenobiotic receptors PXR and CAR for metabolic diseases. Trends Pharmacol. Sci. 33, 552-558.

Gauhar, Z., Sun, L.V., Hua, S.J., Mason, C.E., Fuchs, F., Li, T.R., et al., 2009. Genomic mapping of binding regions for the Ecdysone receptor protein complex. Genome Res. 19, 1006-1013.

Gauthaman, K., Adaikan, P.G., 2005. Effect of Tribulus terrestris on nicotinamide adenine dinucleotide phosphate-diaphorase activity and androgen receptors in rat brain. J. Ethnopharmacol. 96, 127-132.

Germain, P., Chambon, P., Eichele, G., Evans, R.M., Lazar, M.A., Leid, M., et al., 2006. International Union of Pharmacology. LXIII. Retinoid X receptors. Pharmacol. Rev. $58,760-772$.

Gong, Z.W., Huang, C., Sheng, X.Y., Zhang, Y.B., Li, Q.Y., Wang, M.W., et al., 2009. The role of Tanshinone IIA in the treatment of obesity through peroxisome proliferator-activated receptor gamma antagonism. Endocrinology 150, 104-113.

Graham-Rowe, D., 2011. Biodiversity: endangered and in demand. Nature 480, S101-S103.

Grienke, U., Mihaly-Bison, J., Schuster, D., Afonyushkin, T., Binder, M., Guan, S.H., et al., 2011. Pharmacophore-based discovery of FXR-agonists. Part II: identification of bioactive triterpenes from Ganoderma lucidum. Bioorg. Med. Chem. 19, 67796791.

Gronemeyer, H., Gustafsson, J.A., Laudet, V., 2004. Principles for modulation of the nuclear receptor superfamily. Nat. Rev. Drug Discov. 3, 950-964.

Gu, Z.M., Wu, Y.L., Zhou, M.Y., Liu, C.X., Xu, H.Z., Yan, H., et al., 2010. Pharicin B stabilizes retinoic acid receptor-alpha and presents synergistic differentiation induction with ATRA in myeloid leukemic cells. Blood 116, 5289-5297.

Guo, D.Y., Wang, J.Z., Wang, X.Q., Luo, H.J., Zhang, H.Q., Cao, D., et al., 2011. Double directional adjusting estrogenic effect of naringin from Rhizoma drynariae (Gusuibu). J. Ethnopharmacol. 138, 451-457.

Han, H.Y., Shan, S., Zhang, X., Wang, N.L., Lu, X.P., Yao, X.S., 2007. Down-regulation of prostate specific antigen in LNCaP cells by flavonoids from the pollen of Brassica napus L. Phytomedicine 14, 338-343.

Hao, Q., Wang, J., Niu, J., Zhao, P., Cui, Y., Sun, L., et al., 2009. [Study on phytoestrogenic-like effects of four kinds of Chinese medicine including Radix 
Rehmanniae Preparata, Radix Paeoniae Alba, Radix Angelicae Sinensis, Rhizoma Chuanxiong]. Zhongguo Zhong Yao Za Zhi 34, 620-624.

Heldring, N., Pike, A., Andersson, S., Matthews, J., Cheng, G., Hartman, J., et al., 2007. Estrogen receptors: how do they signal and what are their targets. Physiol. Rev. 87, 905-931.

Houck, K.A., Borchert, K.M., Hepler, C.D., Thomas, J.S., Bramlett, K.S., Michael, L.F., et al., 2004. T0901317 is a dual LXR/FXR agonist. Mol. Genet. Metab. 83, 184-187.

Huang, G.S., Hong, M.Y., 2006. Functional and molecular characterization for the damp-obstructed rat model in Chinese medicine. Am. J. Chin. Med. 34 323-340.

Huang, L., Bi, H.C., Liu, Y.H., Wang, Y.T., Xue, X.P., Huang, M., 2011. CAR-mediated up-regulation of CYP3A4 expression in LS174T cells by Chinese herbal compounds. Drug Metab. Pharmacokinet. 26, 331-340.

Huang, P., Chandra, V., Rastinejad, F., 2010. Structural overview of the nuclear receptor superfamily: insights into physiology and therapeutics. Annu. Rev. Physiol. 72, 247-272.

Huang, T.H., Kota, B.P., Razmovski, V., Roufogalis, B.D., 2005. Herbal or natural medicines as modulators of peroxisome proliferator-activated receptors and related nuclear receptors for therapy of metabolic syndrome. Basic Clin. Pharmacol. Toxicol. 96, 3-14.

Huang, T.H., Tran, V.H., Roufogalis, B.D., Li, Y., 2007. Gypenoside XLIX, a naturally occurring PPAR-alpha activator, inhibits cytokine-induced vascular cell adhesion molecule-1 expression and activity in human endothelial cells. Eur. J. Pharmacol. $565,158-165$.

Huang, T.H.W., Li, Y.H., Razmovski-Naumovski, V., Tran, V.H., Li, G.Q., Duke, C.C., et al., 2006. Gypenoside XLIX isolated from Gynostemma pentaphyllum inhibits nuclear factor-kappaB activation via a PPAR-alpha-dependent pathway. J. Biomed. Sci. $13,535-548$

Huang, W., He, T., Chai, C., Yang, Y., Zheng, Y., Zhou, P., et al., 2012. Triptolide inhibits the proliferation of prostate cancer cells and down-regulates SUMO-specific protease 1 expression. PLoS ONE 7, e37693.

Huang, W.D., Zhang, J., Moore, D.D., 2004. A traditional herbal medicine enhances bilirubin clearance by activating the nuclear receptor CAR. J. Clin. Invest. 113, 137-143.

Ji, M., Liu, Y., Yang, S., Zhai, D., Zhang, D., Bai, L., et al., 2013. Puerarin suppresses proliferation of endometriotic stromal cells in part via differential recruitment of nuclear receptor coregulators to estrogen receptor-alpha. J. Steroid Biochem. Mol. Biol. 138, 421-426.

Ji, W., Gong, B.Q., 2007. Hypolipidemic effects and mechanisms of Panax notoginseng on lipid profile in hyperlipidemic rats. J. Ethnopharmacol. 113, 318-324.

Ji, W., Gong, B.Q., 2008. Hypolipidemic activity and mechanism of purified herbal extract of Salvia miltiorrhiza in hyperlipidemic rats. J. Ethnopharmacol. 119, 291-298.

Jiang, M.M., Dai, Y., Gao, H., Zhang, X., Wang, G.H., He, J.Y., et al., 2008. Cardenolides from Antiaris toxicaria as potent selective Nur77 modulators. Chem Pharm Bull (Tokyo) 56, 1005-1008

Jiang, Y., Gong, P., Madak-Erdogan, Z., Martin, T., Jeyakumar, M., Carlson, K., et al., 2013. Mechanisms enforcing the estrogen receptor beta selectivity of botanical estrogens. FASEB J. 27, 4406-4418.

Juan, Y.C., Chang, C.C., Tsai, W.J., Lin, Y.L., Hsu, Y.S., Liu, H.K., 2011. Pharmacological evaluation of insulin mimetic novel suppressors of PEPCK gene transcription from Paeoniae Rubra Radix. J. Ethnopharmacol. 137, 592-600.

Kakizaki, S., Takizawa, D., Tojima, H., Yamazaki, Y., Mori, M., 2009. Xenobiotic-sensing nuclear receptors CAR and PXR as drug targets in cholestatic liver disease. Curr. Drug Targets 10, 1156-1163.

Khorasanizadeh, S., Rastinejad, F., 2001. Nuclear-receptor interactions on DNAresponse elements. Trends Biochem. Sci. 26, 384-390.

Kitareewan, S., Burka, L.T., Tomer, K.B., Parker, C.E., Deterding, L.J., Stevens, R.D., et al. 1996. Phytol metabolites are circulating dietary factors that activate the nuclear receptor RXR. Mol. Biol. Cell 7, 1153-1166.

Kuiper, G.G., Lemmen, J.G., Carlsson, B., Corton, J.C., Safe, S.H., van der Saag, P.T., et al., 1998. Interaction of estrogenic chemicals and phytoestrogens with estrogen receptor beta. Endocrinology 139, 4252-4263.

Lau, A.J., Yang, G., Yap, C.W., Chang, T.K., 2012. Selective agonism of human pregnane $\mathrm{X}$ receptor by individual ginkgolides. Drug Metab. Dispos. 40, 1113-1121.

Lazar, M.A., 2004. East meets West: an herbal tea finds a receptor. J. Clin. Invest. 113, $23-25$

Lee, Y.J., Chung, E., Lee, K.Y., Lee, Y.H., Huh, B., Lee, S.K., 1997. Ginsenoside-Rg1, one of the major active molecules from Panax ginseng, is a functional ligand of glucocorticoid receptor. Mol. Cell. Endocrinol. 133, 135-140.

Lemotte, P.K., Keidel, S., Apfel, C.M., 1996. Phytanic acid is a retinoid X receptor ligand. Eur. J. Biochem. 236, 328-333.

Leung, K.W., Cheng, Y.K., Mak, N.K., Chan, K.K., Fan, T.P., Wong, R.N., 2006a. Signaling pathway of ginsenoside-Rg1 leading to nitric oxide production in endothelial cells. FEBS Lett. 580, 3211-3216.

Leung, K.W., Pon, Y.L., Wong, R.N., Wong, A.S., 2006b. Ginsenoside-Rg1 induces vascular endothelial growth factor expression through the glucocorticoid receptor-related phosphatidylinositol 3-kinase/Akt and beta-catenin/T-cell factor-dependent pathway in human endothelial cells. J. Biol. Chem. 281 36280-36288.

Leung, K.W., Leung, F.P., Huang, Y., Mak, N.K., Wong, R.N., 2007a. Non-genomic effects of ginsenoside-Re in endothelial cells via glucocorticoid receptor. FEBS Lett. 581, 2423-2428.

Leung, K.W., Yung, K.K., Mak, N.K., Chan, Y.S., Fan, T.P., Wong, R.N., 2007b Neuroprotective effects of ginsenoside-Rg1 in primary nigral neurons against rotenone toxicity. Neuropharmacology 52, 827-835.
Li, J., Zhang, J.Z., Zou, C.P., Fang, B.J., Liang, X.Q., 2008. [Shengqing Capsule downregulates estrogen and progesterone receptors in epithelial tissue of gallbladder in guinea pigs with gallstone]. Zhong Xi Yi Jie He Xue Bao 6, 1040-1044.

Li, J.W., Vederas, J.C., 2009. Drug discovery and natural products: end of an era or an endless frontier? Science 325, 161-165.

Li, L., Stanton, J.D., Tolson, A.H., Luo, Y., Wang, H., 2009a. Bioactive terpenoids and flavonoids from Ginkgo biloba extract induce the expression of hepatic drugmetabolizing enzymes through pregnane $X$ receptor, constitutive androstane receptor, and aryl hydrocarbon receptor-mediated pathways. Pharm. Res. 26 $872-882$.

Li, M., Ling, C.Q., Huang, X.Q., Shen, Z.L., 2006. [Effects of ginsenosides extracted from ginseng stem and leaves on glucocorticoid receptor in different viscera in heat-damaged rats]. Zhong Xi Yi Jie He Xue Bao 4, 156-159.

Li, W., Chen, Z., Liao, Y., Liu, H., 2005. Separation methods for toxic components in traditional Chinese medicines. Anal. Sci. 21, 1019-1029.

Li, X.J., Zhang, H.Y., 2008. Synergy in natural medicines: implications for drug discovery. Trends Pharmacol. Sci. 29, 331-332.

Li, Y., 2004. [Relationship between glucocorticoid receptor and deficiency syndrome and the regulation of traditional Chinese medicine]. Zhong Xi Yi Jie He Xue Bao 2, 172-174.

Li, Y., Zhang, D.L., Wang, P., 2009b. [Effect of ginsenosides on level of sex hormone receptors in human liver cell line HL-7702]. Zhongguo Zhong Xi Yi Jie He Za Zhi $29,1110-1113$.

Lichti-Kaiser, K., Staudinger, J.L., 2008. The traditional Chinese herbal remedy tian xian activates pregnane $\mathrm{X}$ receptor and induces CYP3A gene expression in hepatocytes. Drug Metab. Dispos. 36, 1538-1545.

Lim, S.H., Ha, T.Y., Kim, S.R., Ahn, J., Park, H.J., Kim, S., 2009. Ethanol extract of Psoralea corylifolia L. and its main constituent, bakuchiol, reduce bone loss in ovariectomised Sprague-Dawley rats. Br. J. Nutr. 101, 1031-1039.

Lin, H.R., 2012. Sesquiterpene lactones from Tithonia diversifolia act as peroxisome proliferator-activated receptor agonists. Bioorg Med Chem Lett 22, 2954-2958.

Lin, P.C., Chen, Y.L., Chiu, S.C., Yu, Y.L., Chen, S.P., Chien, M.H., et al., 2008. Orphan nuclear receptor, Nurr-77 was a possible target gene of butylidenephthalide chemotherapy on glioblastoma multiform brain tumor. J. Neurochem. 106, 1017-1026.

Ling, C., Li, Y., Zhu, X., Zhang, C., Li, M., 2005. Ginsenosides may reverse the dexamethasone-induced down-regulation of glucocorticoid receptor. Gen. Comp. Endocrinol. 140, 203-209.

Liu, J., Jiang, Z., Xiao, J., Zhang, Y., Lin, S., Duan, W., et al., 2009. Effects of triptolide from Tripterygium wilfordii on ERalpha and p53 expression in two human breast cancer cell lines. Phytomedicine 16, 1006-1013.

Liu, L., Shan, S., Zhang, K., Ning, Z.Q., Lu, X.P., Cheng, Y.Y., 2008a. Naringenin and hesperetin, two flavonoids derived from Citrus aurantium up-regulate transcription of adiponectin. Phytother. Res. 22, 1400-1403.

Liu, L., Ma, H., Tang, Y., Chen, W., Lu, Y., Guo, J., et al., 2012. Discovery of estrogen receptor alpha modulators from natural compounds in Si-Wu-Tang series decoctions using estrogen-responsive MCF-7 breast cancer cells. Bioorg. Med. Chem. Lett. 22, 154-163.

Liu, Q., Tang, J.S., Hu, M.J., Liu, J., Chen, H.F., Gao, H., et al., 2013a. Antiproliferative cardiac glycosides from the latex of Antiaris toxicaria. J. Nat. Prod. 76, 1771-1780.

Liu, W.M., Wong, C.W., 2010. Oleanolic acid is a selective farnesoid X receptor modulator. Phytother. Res. 24, 369-373.

Liu, Y., Wang, K.G., Ye, W., 2008b. [Relation of phlegm-stasis syndrome with insulin resistance and monocyte PPARgamma mRNA expression in patients with coronary heart disease]. Zhongguo Zhong Xi Yi Jie He Za Zhi 28, 602-605.

Liu, Y.H., Mo, S.L., Bi, H.C., Hu, B.F., Li, C.G., Wang, Y.T., et al., 2011. Regulation of human pregnane $\mathrm{X}$ receptor and its target gene cytochrome P450 3A4 by Chinese herbal compounds and a molecular docking study. Xenobiotica 41, 259-280.

Liu, Z.L., Xie, L.Z., Zhu, J., Li, G.Q., Grant, S.J., Liu, J.P., 2013b. Herbal medicines for fatty liver diseases. Cochrane Database Syst. Rev. (8), CD009059.

Lo-Coco, F., Avvisati, G., Vignetti, M., Thiede, C., Orlando, S.M., Iacobelli, S., et al., 2013. Retinoic acid and arsenic trioxide for acute promyelocytic leukemia. N. Engl. J. Med. 369, 111-121.

Lonard, D.M., O'Malley, B.W., 2012. Nuclear receptor coregulators: modulators of pathology and therapeutic targets. Nat Rev Endocrinol 8, 598-604.

Lonard, D.M., Smith, C.L., 2002. Molecular perspectives on selective estrogen receptor modulators (SERMs): progress in understanding their tissue-specific agonist and antagonist actions. Steroids 67, 15-24.

Lu, J.P., Cai, D.P., 2008. [Regulative effects of Chinese herbs for nourishing yin and removing fire on gene expressions of estrogen receptor alpha, insulin-like growth factor-1 receptor, epithelial growth factor receptor and protein synthesis in epiphyseal growth plate of female pubertal rats]. Zhongguo Zhong Xi Yi Jie He Za Zhi 28, 721-724.

Ma, H., Chung, M.H., Lu, Y., Nishihara, T., Hattori, M., 2010. Estrogenic effects of the herbal formula, menoprogen, in ovariectomized rats. Biol. Pharm. Bull. 33 , 455-460.

Mahomoodally, M.F., 2013. Traditional medicines in Africa: an appraisal of ten potent african medicinal plants. Evid. Based Complement. Alternat. Med. 2013, 617459.

Makishima, M., Lu, T.T., Xie, W., Whitfield, G.K., Domoto, H., Evans, R.M., et al., 2002 Vitamin D receptor as an intestinal bile acid sensor. Science 296, 1313-1316.

May, B.H., Lu, C., Xue, C.C., 2012. Collections of traditional Chinese medical literature as resources for systematic searches. J. Altern. Complement. Med. 18, 11011107.

Mersereau, J.E., Levy, N., Staub, R.E., Baggett, S., Zogovic, T., Chow, S., et al., 2008 Liquiritigenin is a plant-derived highly selective estrogen receptor beta agonist. Mol. Cell. Endocrinol. 283, 49-57. 
Meyer, U., Costantino, G., Macchiarulo, A., Pellicciari, R., 2005. Is antagonism of $\mathrm{E} / \mathrm{Z}$-guggulsterone at the farnesoid $\mathrm{X}$ receptor mediated by a noncanonical binding site? A molecular modeling study. J. Med. Chem. 48, 6948-6955.

Michel, J., Duarte, R.E., Bolton, J.L., Huang, Y., Caceres, A., Veliz, M., et al., 2007. Medical potential of plants used by the Q'eqchi Maya of Livingston, Guatemala for the treatment of women's health complaints. J. Ethnopharmacol. $114,92-101$.

Miller, L.H., Su, X., 2011. Artemisinin: discovery from the Chinese herbal garden. Cell $146,855-858$.

Monden, T., Hosoya, T., Nakajima, Y., Kishi, M., Satoh, T., Hashimoto, K., et al., 2008. Herbal medicine, Hachimi-jio-gan, and its component cinnamomi cortex activate the peroxisome proliferator-activated receptor alpha in renal cells. Endocr. J. 55, 529-533.

Moore, D.D., Kato, S., Xie, W., Mangelsdorf, D.J., Schmidt, D.R., Xiao, R., et al., 2006. International Union of Pharmacology. LXII. The NR1H and NR1I receptors: constitutive androstane receptor, pregnene $\mathrm{X}$ receptor, farnesoid $\mathrm{X}$ receptor alpha, farnesoid X receptor beta, liver X receptor alpha, liver X receptor beta, and vitamin D receptor. Pharmacol. Rev. 58, 742-759.

Moore, L.B., Goodwin, B., Jones, S.A., Wisely, G.B., Serabjit-Singh, C.J., Willson, T.M., et al., 2000. St. John's wort induces hepatic drug metabolism through activation of the pregnane X receptor. Proc. Natl. Acad. Sci. U.S.A. 97, 7500-7502.

Moore, T.W., Mayne, C.G., Katzenellenbogen, J.A., 2010. Minireview: not picking pockets: nuclear receptor alternate-site modulators (NRAMs). Mol. Endocrinol. 24, 683-695

Mu, Y., Zhang, J., Zhang, S., Zhou, H.H., Toma, D., Ren, S., et al., 2006. Traditional Chinese medicines Wu Wei Zi (Schisandra chinensis Baill) and Gan Cao (Glycyrrhiza uralensis Fisch) activate pregnane $\mathrm{X}$ receptor and increase warfarin clearance in rats. J. Pharmacol. Exp. Ther. 316, 1369-1377.

Mueller, S.O., 2002. Overview of in vitro tools to assess the estrogenic and antiestrogenic activity of phytoestrogens. J. Chromatogr. B. Analyt Technol Biomed Life Sci. 777, 155-165.

Nakano, H., Matsunawa, M., Yasui, A., Adachi, R., Kawana, K., Shimomura, I., et al., 2005. Enhancement of ligand-dependent Vitamin D receptor transactivation by the cardiotonic steroid bufalin. Biochem. Pharmacol. 70, 1479-1486.

Onogi, K., Niwa, K., Tang, L., Yun, W., Mori, H., Tamaya, T., 2006. Inhibitory effects of Hochu-ekki-to on endometrial carcinogenesis induced by $\mathrm{N}$-methyl-N-nitrosourea and 17beta-estradiol in mice. Oncol. Rep. 16, 1343-1348.

Pawlak, M., Lefebvre, P., Staels, B., 2012. General molecular biology and architecture of nuclear receptors. Curr. Top. Med. Chem. 12, 486-504.

Pearen, M.A., Muscat, G.E., 2010. Minireview: nuclear hormone receptor 4A signaling: implications for metabolic disease. Mol. Endocrinol. 24, 1891-1903.

Perissi, V., Rosenfeld, M.G., 2005. Controlling nuclear receptors: the circular logic of cofactor cycles. Nat. Rev. Mol. Cell Biol. 6, 542-554.

Perissi, V., Jepsen, K., Glass, C.K., Rosenfeld, M.G., 2010. Deconstructing repression: evolving models of co-repressor action. Nat. Rev. Genet. 11, 109-123.

Pickar, J.H., MacNeil, T., Ohleth, K., 2010. SERMs: progress and future perspectives. Maturitas 67, 129-138.

Powell, E., Xu, W., 2008. Intermolecular interactions identify ligand-selective activity of estrogen receptor alpha/beta dimers. Proc. Natl. Acad. Sci. U.S.A. 105, 1901219017

Qiu, J., 2007. Traditional medicine: a culture in the balance. Nature 448, 126-128.

Robinson-Rechavi, M., Carpentier, A.S., Duffraisse, M., Laudet, V., 2001. How many nuclear hormone receptors are there in the human genome? Trends Genet. 17, 554-556.

Rocchi, S., Picard, F., Vamecq, J., Gelman, L., Potier, N., Zeyer, D., et al., 2001. A unique PPARgamma ligand with potent insulin-sensitizing yet weak adipogenic activity. Mol. Cell 8, 737-747.

Rubenstrunk, A., Hanf, R., Hum, D.W., Fruchart, J.C., Staels, B., 2007. Safety issues and prospects for future generations of PPAR modulators. Biochim. Biophys. Acta 1771, 1065-1081.

Samarut, E., Rochette-Egly, C., 2012. Nuclear retinoic acid receptors: conductors of the retinoic acid symphony during development. Mol. Cell. Endocrinol. 348, 348-360.

Samarut, E. Gaudin, C., Hughes, S., Gillet, B., de Bernard, S., Jouve, P.E, et al., 2014 Retinoic acid receptor subtype-specific transcriptotypes in the early zebrafish embryo. Mol. Endocrinol. 28, 260-272.

Scheid, V., 1999. The globalization of Chinese medicine. Lancet 354 (Suppl.), SIV10.

Shen, T., Li, G.H., Wang, X.N., Lou, H.X., 2012. The genus Commiphora: a review of its traditional uses, phytochemistry and pharmacology. J. Ethnopharmacol. 142, 319-330.

Shen, Z.X., Chen, G.Q., Ni, J.H., Li, X.S., Xiong, S.M., Qiu, Q.Y., et al., 1997. Use of arsenic trioxide (As203) in the treatment of acute promyelocytic leukemia (APL): II. Clinical efficacy and pharmacokinetics in relapsed patients. Blood 89, 33543360.

Sheng, X., Wang, M., Lu, M., Xi, B., Sheng, H., Zang, Y.Q., 2011. Rhein ameliorates fatty liver disease through negative energy balance, hepatic lipogenic regulation, and immunomodulation in diet-induced obese mice. Am. J. Physiol. Endocrinol. Metab. 300, E886-E893.

Simpson, B.S., Claudie, D.J., Smith, N.M., McKinnon, R.A., Semple, S.J., 2013. Learning from both sides: experiences and opportunities in the investigation of Australian aboriginal medicinal plants. J. Pharm. Pharm. Sci. 16, 259-271.

Sladek, F.M., 2010. What are nuclear receptor ligands? Mol. Cell. Endocrinol. 334, 3-13.

Souza, P.C., Puhl, A.C., Martinez, L., Aparicio, R., Nascimento, A.S., Figueira, A.C., et al., 2014. Identification of a new hormone-binding site on the surface of thyroid hormone receptor. Mol. Endocrinol. 28, 534-545.
Suk, F.M., Lin, S.Y., Chen, C.H., Yen, S.J., Su, C.H., Liu, D.Z., et al., 2008. Taiwanofungus camphoratus activates peroxisome proliferator-activated receptors and induces hypotriglyceride in hypercholesterolemic rats. Biosci. Biotechnol. Biochem. 72 1704-1713.

Swart, P., Swart, A.C., Louw, A., van der Merwe, K.J., 2003. Biological activities of the shrub Salsola tuberculatiformis Botsch.: contraceptive or stress alleviator? Bioessays 25, 612-619.

Tian, P., 2011. Convergence: where West meets East. Nature 480, S84-S86.

Tian, L.J., Huang, T.K., 2007. Research of Traditional Chinese Medicine Phylogeny. Chin Arch Tradit Chin Med 25, 753-755.

Tseng, Y.P., Wu, Y.C., Leu, Y.L., Yeh, S.F., Chou, C.K., 2010. Scutellariae radix suppresses hepatitis B virus production in human hepatoma cells. Front Biosci (Elite Ed) 2, 1538-1547.

Tu, Y., 2011. The discovery of artemisinin (qinghaosu) and gifts from Chinese medicine. Nat. Med. 17, 1217-1220.

Urizar, N.L., Liverman, A.B., Dodds, D.T., Silva, F.V., Ordentlich, P., Yan, Y., et al., 2002. A natural product that lowers cholesterol as an antagonist ligand for FXR. Science 296, 1703-1706.

Wang, Q., Yao, S.L., 2008. Molecular Basis for Cold-Intolerant YangDeficient Constitution of Traditional Chinese Medicine. Am. J. Chin. Med. 36 827-834.

Wang, L., Zhou, G.B., Liu, P., Song, J.H., Liang, Y., Yan, X.J., et al., 2008. Dissection of mechanisms of Chinese medicinal formula Realgar-Indigo naturalis as an effective treatment for promyelocytic leukemia. Proc. Natl. Acad. Sci. U.S.A. 105, 48264831.

Wang, M.W., Hao, X., Chen, K., 2007. Biological screening of natural products and drug innovation in China. Philos. Trans. R. Soc. Lond. B. Biol Sci. 362, 10931105 .

Wang, X., Zhang, A., Sun, H., 2012a. Future perspectives of Chinese medical formulae: chinmedomics as an effector. OMICS 16, 414-421.

Wang, X., Zhang, H., Chen, L., Shan, L., Fan, G., Gao, X., 2013. Liquorice, a unique "guide drug" of traditional Chinese medicine: a review of its role in drug interactions. J. Ethnopharmacol. 150, 781-790.

Wang, Y.G., Zhou, J.M., Ma, Z.C., Li, H., Liang, Q.D., Tan, H.L., et al., 2012b. Pregnane $\mathrm{X}$ receptor mediated-transcription regulation of CYP3A by glycyrrhizin: a possible mechanism for its hepatoprotective property against lithocholic acid-induced injury. Chem. Biol. Interact. 200, 11-20.

Wang, Z., Benoit, G., Liu, J., Prasad, S., Aarnisalo, P., Liu, X., et al., 2003. Structure and function of Nurr1 identifies a class of ligand-independent nuclear receptors. Nature 423, 555-560.

Wang, Z., Liu, J., Cheng, Y., Wang, Y., 2011. Fangjiomics: in search of effective and safe combination therapies. J. Clin. Pharmacol. 51, 1132-1151.

Watkins, R.E., Wisely, G.B., Moore, L.B., Collins, J.L., Lambert, M.H., Williams, S.P., et al., 2001. The human nuclear xenobiotic receptor PXR: structural determinants of directed promiscuity. Science 292, 2329-2333.

Watkins, R.E., Maglich, J.M., Moore, L.B., Wisely, G.B., Noble, S.M., Davis-Searles, P.R., et al., 2003. 2.1 A crystal structure of human PXR in complex with the St. John's wort compound hyperforin. Biochemistry 42, 1430-1438.

Weng, J.R., Bai, L.Y., Chiu, C.F., Hu, J.L., Chiu, S.J., Wu, C.Y., 2013. Cucurbitane triterpenoid from Momordica charantia induces apoptosis and autophagy in breast cancer cells, in part, through peroxisome proliferator-activated receptor gamma activation. Evid. Based Complement. Alternat. Med. 2013 935675.

Willson, T.M., Kliewer, S.A., 2002. PXR, CAR and drug metabolism. Nat. Rev. Drug Discov. 1, 259-266.

Wu, C.Y., Hsieh, C.Y., Huang, K.E., Chang, C., Kang, H.Y., 2012a. Cryptotanshinone down-regulates androgen receptor signaling by modulating lysine-specific demethylase 1 function. Int. J. Cancer 131, 1423-1434.

Wu, J., Xia, C., Meier, J., Li, S., Hu, X., Lala, D.S., 2002. The hypolipidemic natural product guggulsterone acts as an antagonist of the bile acid receptor. Mol. Endocrinol. 16, 1590-1597.

Wu, J., Pan, Z., Wang, Z., Zhu, W., Shen, Y., Cui, R., et al., 2012b. Ginsenoside Rg1 protection against beta-amyloid peptide-induced neuronal apoptosis via estrogen receptor alpha and glucocorticoid receptor-dependent anti-protein nitration pathway. Neuropharmacology 63, 349-361.

Wu, J., Pan, Z., Cheng, M., Shen, Y., Yu, H., Wang, Q., et al., 2013. Ginsenoside Rg1 facilitates neural differentiation of mouse embryonic stem cells via GR-dependent signaling pathway. Neurochem. Int. 62, 92-102.

Wu, K.M., Farrelly, J.G., Upton, R., Chen, J., 2007. Complexities of the herbal nomenclature system in traditional Chinese medicine (TCM): lessons learned from the misuse of Aristolochia-related species and the importance of the pharmaceutical name during botanical drug product development. Phytomedicine 14, 273-279.

Xin, D., Wang, H., Yang, J., Su, Y.F., Fan, G.W., Wang, Y.F., et al., 2010. Phytoestrogens from Psoralea corylifolia reveal estrogen receptor-subtype selectivity. Phytomedicine 17, 126-131.

Xu, D., Lin, T.H., Li, S., Da, J., Wen, X.Q., Ding, J., et al., 2012. Cryptotanshinone suppresses androgen receptor-mediated growth in androgen dependent and castration resistant prostate cancer cells. Cancer Lett. 316, 11-22.

Xue, R., Fang, Z., Zhang, M., Yi, Z., Wen, C., Shi, T., 2013. TCMID: Traditional Chinese Medicine integrative database for herb molecular mechanism analysis. Nucleic Acids Res. 41, D1089-D1095.

Yang, C.S., Ko, S.R., Cho, B.G., Shin, D.M., Yuk, J.M., Li, S., et al., 2008a. The ginsenoside metabolite compound $\mathrm{K}$, a novel agonist of glucocorticoid receptor induces tolerance to endotoxin-induced lethal shock. J. Cell. Mol. Med. 12, 1739-1753. 
Yang, H., Chen, D., Cui, Q.C., Yuan, X., Dou, Q.P., 2006. Celastrol, a triterpene extracted from the Chinese "Thunder of God Vine," is a potent proteasome inhibitor and suppresses human prostate cancer growth in nude mice. Cancer Res. 66, 4758-4765.

Yang, J., Wang, Y., Bao, Y., Guo, J., 2008b. The total flavones from Semen cuscutae reverse the reduction of testosterone level and the expression of androgen receptor gene in kidney-yang deficient mice. J. Ethnopharmacol. 119, 166-171.

Yang, M.H., Wang, H.M., Liu, Y., 2011. Effect of Bushen Huoxue Decoction on the orphan receptor and tyrosine hydroxylase in the brain of rats with Parkinson's disease. Chin. J. Integr. Med. 17, 43-47.

Yang, L., Broderick, D., Jiang, Y., Hsu, V., Maier, C.S., 2014. Conformational dynamics of human FXR-LBD ligand interactions studied by hydrogen/deuterium exchange mass spectrometry: insights into the antagonism of the hypolipidemic agent Z-guggulsterone. Biochim. Biophys. Acta 1844, 1684-1693.

Yang, M.H., Vasquez, Y., Ali, Z., Khan, I.A., Khan, S.I., 2013. Constituents from Terminalia species increase PPARalpha and PPARgamma levels and stimulate glucose uptake without enhancing adipocyte differentiation. J. Ethnopharmacol. 149, 490-498.

Yu, C., Chai, X., Yu, L., Chen, S., Zeng, S., 2011. Identification of novel pregnane X receptor activators from traditional Chinese medicines. J. Ethnopharmacol. 136, 137-143.

Yu, C.N., Ye, S.S., Sun, H.Y., Liu, Y., Gao, L.B., Shen, C.F., et al., 2009. PXR-mediated transcriptional activation of CYP3A4 by cryptotanshinone and tanshinone IIA. Chem. Biol. Interact. 177, 58-64.

Zhang, C.Z., Wang, S.X., Zhang, Y., Chen, J.P., Liang, X.M., 2005. In vitro estrogenic activities of Chinese medicinal plants traditionally used for the management of menopausal symptoms. J. Ethnopharmacol. 98, 295-300.
Zhang, H., Ma, J., 2010. [Effects of jingqianshu granule on expression of estrogen receptor alpha and beta mRNA in hypothalamus and hippocampus of PMS rats with liver-qi depression]. Zhongguo Zhong Yao Za Zhi 35, 489492.

Zhang, H., Chen, L., Chen, J., Jiang, H., Shen, X., 2011a. Structural basis for retinoic X receptor repression on the tetramer. J. Biol. Chem. 286, 24593-24598.

Zhang, H., Li, L., Chen, L., Hu, L., Jiang, H., Shen, X., 2011b. Structure basis of bigelovin as a selective RXR agonist with a distinct binding mode. J. Mol. Biol. $407,13-20$.

Zhang, H., Zhou, R., Li, L., Chen, J., Chen, L., Li, C., et al., 2011c. Danthron functions as a retinoic $\mathrm{X}$ receptor antagonist by stabilizing tetramers of the receptor. J. Biol. Chem. 286, 1868-1875.

Zhang, K., Lu, J., Mori, T., Smith-Powell, L., Synold, T.W., Chen, S., et al., 2011d. Baicalin increases VEGF expression and angiogenesis by activating the ERR\{alpha\}/PGC1 \{alpha\} pathway. Cardiovasc. Res. 89, 426-435.

Zhang, Y., Won, S.H., Jiang, C., Lee, H.J., Jeong, S.J., Lee, E.O., et al., 2012. Tanshinones from Chinese medicinal herb Danshen (Salvia miltiorrhiza Bunge) suppress prostate cancer growth and androgen receptor signaling. Pharm. Res. 29, 1595-1608.

Zhang, Z., Burch, P.E., Cooney, A.J., Lanz, R.B., Pereira, F.A., Wu, J., et al., 2004. Genomic analysis of the nuclear receptor family: new insights into structure, regulation, and evolution from the rat genome. Genome Res. 14, 580-590.

Zhou, L., Tang, Y.P., Gao, L., Fan, X.S., Liu, C.M., Wu, D.K., 2009. Separation, characterization and dose-effect relationship of the PPARgamma-activating bio-active constituents in the Chinese herb formulation 'San-Ao decoction'. Molecules 14, 3942-3951. 